\title{
Toward more sustainable chemical activation strategies for the production of porous carbons
}

\author{
Marta Sevilla, Noel Díez and Antonio B. Fuertes
}

\begin{abstract}
The preparation of porous carbons attracts a great deal of attention given the importance of these materials in many emerging applications such as hydrogen storage, $\mathrm{CO}_{2}$ capture, and energy storage in supercapacitors, batteries, etc. In particular, porous carbons produced by applying chemical activation methods are preferred because of the high pore development achieved. However, given the environmental risks associated with conventional activating agents (e.g., $\mathrm{KOH}$ ), the development of greener chemical activation methodologies is an important objective. Herein, we review recent progress in the production of porous carbons by using more sustainable strategies based on chemical activation. The use of less-corrosive chemical agents as an alternative to $\mathrm{KOH}$ is thoroughly reviewed. In addition, we look in detail at the progress achieved so far using emerging self-activation methodologies applied to organic salts and biomass products.
\end{abstract}

Dr. M. Sevilla, Dr. Noel Díez, Prof. A. B. Fuertes

Instituto de Ciencia y Tecnología del Carbono, INCAR-CSIC

Francisco Pintado Fe, 26. 33011 Oviedo (Spain)

E-mail: abefu@incar.csic.es 


\section{Introduction}

Basically, a porous carbon can be described as a material made up of randomly arranged defective graphene layers that enclose numerous interconnected nanocavities (pores). Due to the presence of these small cavities, porous carbons can achieve high internal pore volumes $\left(>1 \mathrm{~cm}^{3} \mathrm{~g}^{-1}\right)$ and surface areas that can exceed $3500 \mathrm{~m}^{2} \mathrm{~g}^{-1}$. Apart from pore development, porous carbons have other important properties that are crucial in many applications. They have good electrical conductivity and chemical inertness, and can be easily functionalized by the insertion of a variety of heteroatoms such as $N, O, S, B$, etc. $^{[1]}$ The importance of porous carbons lies in the fact that they are very useful in a wide range of applications, such as: a) removal of pollutants in liquid (usually water) ${ }^{[2]}$ or gas (usually air) ${ }^{[3]}$ phases, b) separation of gas mixtures (carbon molecular sieves) ${ }^{[4,5]}$ c) storage of gases such as methane ${ }^{[6]}$ or hydrogen, ${ }^{[7,8]}$ d) $\mathrm{CO}_{2}$ adsorption, ${ }^{9,10]}$ e) as catalysts or catalytic support, etc. ${ }^{[11]}$ In the last twenty years, there has been renewed interest in the fabrication of porous carbons due to their key role in electrochemical energy storage systems such supercapacitors, batteries ( $\mathrm{Li}, \mathrm{Li}-\mathrm{S}, \mathrm{Na}, \mathrm{K}$, etc.) and hybrid ion capacitors. $^{[8,12-15]}$

There are two requirements for the raw organic materials to be used as precursors of porous carbons: a) they must be able to produce significant carbon residue after heat treatment under an inert atmosphere, and ii) they must give rise to carbons with a disordered microstructure (non-graphitizable carbon). The materials that meet both characteristics include biomass or biomass-derived products (e.g., saccharides and bio-polymers), coal/petroleum and certain types of polymers. Nowadays, biomass is the preferred precursor due to its Earth abundance, sustainability and low cost. Usually, the production of porous carbon (activation) is based on the reaction between the carbonaceous precursor and certain substances (activating agents) that induce a controlled removal of a number of carbon atoms, which causes the formation of numerous internal pores. When the activating agents are reactive gases such as carbon dioxide or steam, the activation process is called physical activation, which usually requires long reaction times at temperatures $>800{ }^{\circ} \mathrm{C}^{[16,17]} \mathrm{An}$ alternative route for producing porous carbons is known as the chemical activation process, which involves the co-carbonization of the carbonaceous matter with certain chemical substances $\left(\mathrm{KOH}, \mathrm{NaOH}, \mathrm{ZnCl}_{2}\right.$ or $\left.\mathrm{H}_{3} \mathrm{PO}_{4}\right)$ that, at high temperatures, act as oxidizing agents promoting the creation of numerous pores. ${ }^{[18-21]}$ Compared to physical activation, chemical activation processes yield porous carbons that have higher pore development (pore volumes $>1 \mathrm{~cm}^{3}$ $\mathrm{g}^{-1}$ and BET surface areas $>2000 \mathrm{~m}^{2} \mathrm{~g}^{-1}$ ) and a pore network that usually combines micro- and mesopores. Owing to these superior textural characteristics, this methodology has been the subject of great interest for the production of highly porous carbons that are ideal for several emergent applications such as $\mathrm{H}_{2}$ storage ${ }^{[8,22,23]} \mathrm{CO}_{2}$ capture, ${ }^{[24-26]}$ and as electrodes in electrochemical applications such as supercapacitors, ${ }^{[8,15,27]}$ Li-S batteries, ${ }^{[28]}$ and hybrid-ion capacitors. ${ }^{[29]}$ However, the chemical activation agents noted above, and in particular the most frequently used $\mathrm{KOH}$, are highly corrosive substances categorized as "Extreme Danger" as shown in Figure 1. This severely limits their use at an industrial level and, consequently, most of the commercially available porous carbons for electrochemical applications 
(Kuraray, Norit) are produced by means of physical activation. Accordingly, it is imperative to introduce more benign activating chemical agents as well as implementing greener activation techniques in order to scale-up chemical activation from its current laboratory scale to an industrial level.

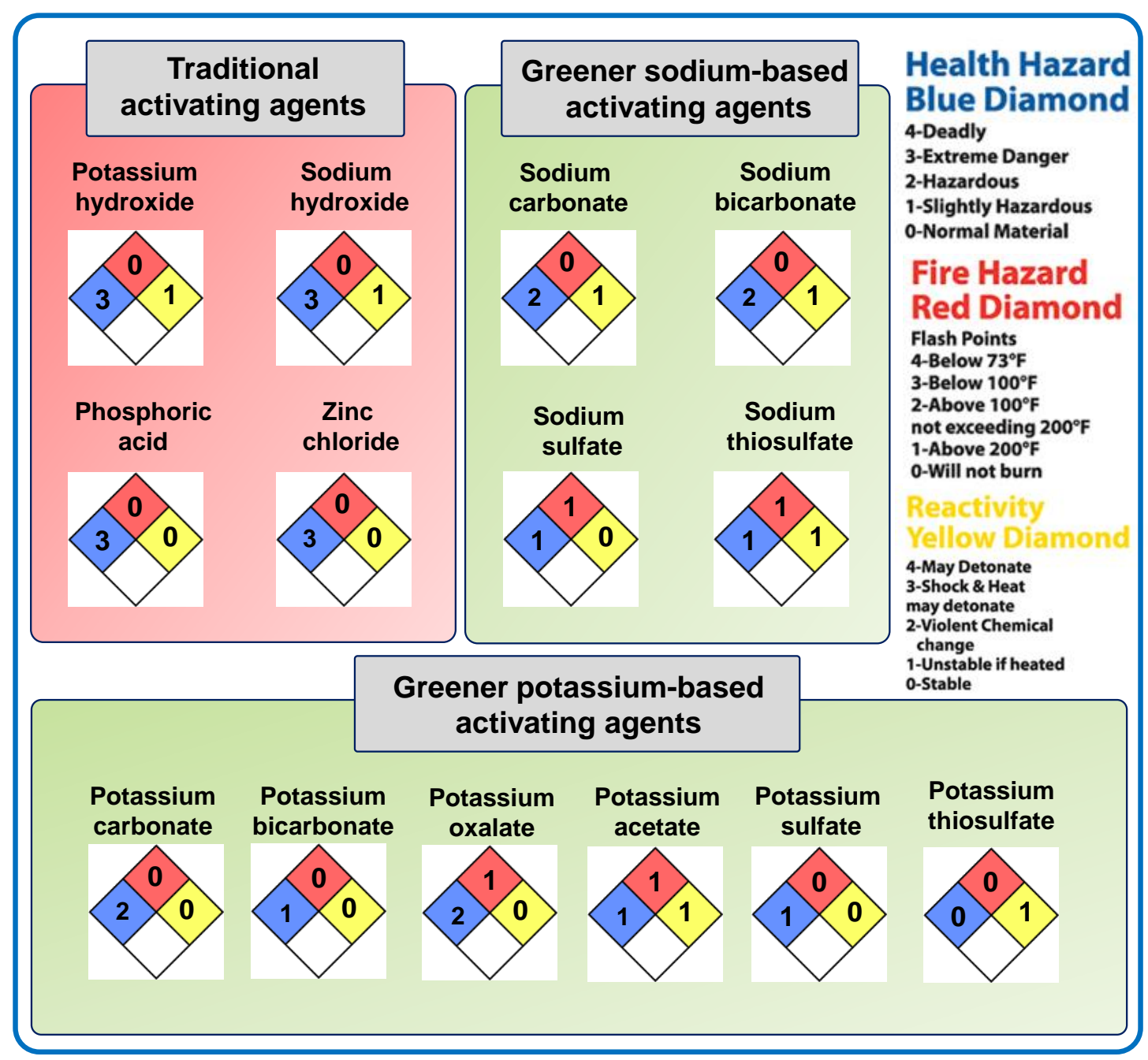

Figure 1. NFPA 704 hazard labels of different chemical activating agents.

Unlike other recent reviews focused on the production of porous carbons for specific applications or from a specific precursor such as biomass, ${ }^{[13,27,30-32]}$ this review is exclusively focused on the preparation of porous carbons using more environmentally friendly chemical activation strategies. First, we discuss recent advances in the synthesis of porous carbons by means of chemical activation using less-corrosive chemical agents. We place particular emphasis on understanding the operating reaction mechanisms and on the evaluation of textural properties. Subsequently, we look in detail at the progress achieved through emerging strategies to produce porous carbon by using self-activation techniques. We perform thorough review of different types of organic salts of $\mathrm{K}$, $\mathrm{Na}, \mathrm{Ca}, \mathrm{Fe}$ and $\mathrm{Zn}$ that are able to generate porous carbons by means of a simple one-step carbonization. In addition, bearing in mind the great practical importance of using biomass as a carbon precursor, we analyze the selfactivation processes applied to biomass products in depth. 


\section{Harmless chemical activating agents}

\subsection{Alkali metal carbonates and bicarbonates}

Given that $\mathrm{KOH}$ is one of the most powerful activating agents, researchers have analyzed the efficiency of other potassium salts. One of the oldest, which is in fact one of the reaction products during potassium hydroxide activation, is potassium carbonate. Compared to $\mathrm{KOH}, \mathrm{K}_{2} \mathrm{CO}_{3}$ is a milder basic compound, less toxic and corrosive, as can be seen in its corresponding NFPA 704 hazard label (see Figure 1). The porogenic action of $\mathrm{K}_{2} \mathrm{CO}_{3}$, schematically illustrated in Figure 2 , is based on a redox reaction with carbon, according to: ${ }^{[33,34]}$

$\mathrm{K}_{2} \mathrm{CO}_{3}+2 \mathrm{C} \rightarrow 2 \mathrm{~K}+3 \mathrm{CO}$

in which potassium carbonate oxidizes the carbonaceous matter to $\mathrm{CO}$ yielding porosity in the carbon residue. In addition, potassium vapors may intercalate between the graphene layers to cause swelling and the disruption of the carbon microstructure, which thereby generates additional porosity. ${ }^{[35,36]}$ Also, for temperatures higher than $850^{\circ} \mathrm{C}, \mathrm{K}_{2} \mathrm{CO}_{3}$ slowly decomposes following the reaction::[37]

$\mathrm{K}_{2} \mathrm{CO}_{3} \rightarrow \mathrm{K}_{2} \mathrm{O}+\mathrm{CO}_{2}$

Both activation products can lead to further activation of the carbon. Thus, the $\mathrm{CO}_{2}$ reacts with carbon creating new pores or enlarging the existing ones, according to the Boudouard reaction:

$\mathrm{C}+\mathrm{CO}_{2} \rightarrow 2 \mathrm{CO}$

On the other hand, the $\mathrm{K}_{2} \mathrm{O}$ can be reduced by carbon to $\mathrm{K}$, etching additional carbon atoms in the following manner:

$\mathrm{K}_{2} \mathrm{O}+\mathrm{C} \rightarrow 2 \mathrm{~K}+\mathrm{CO}$

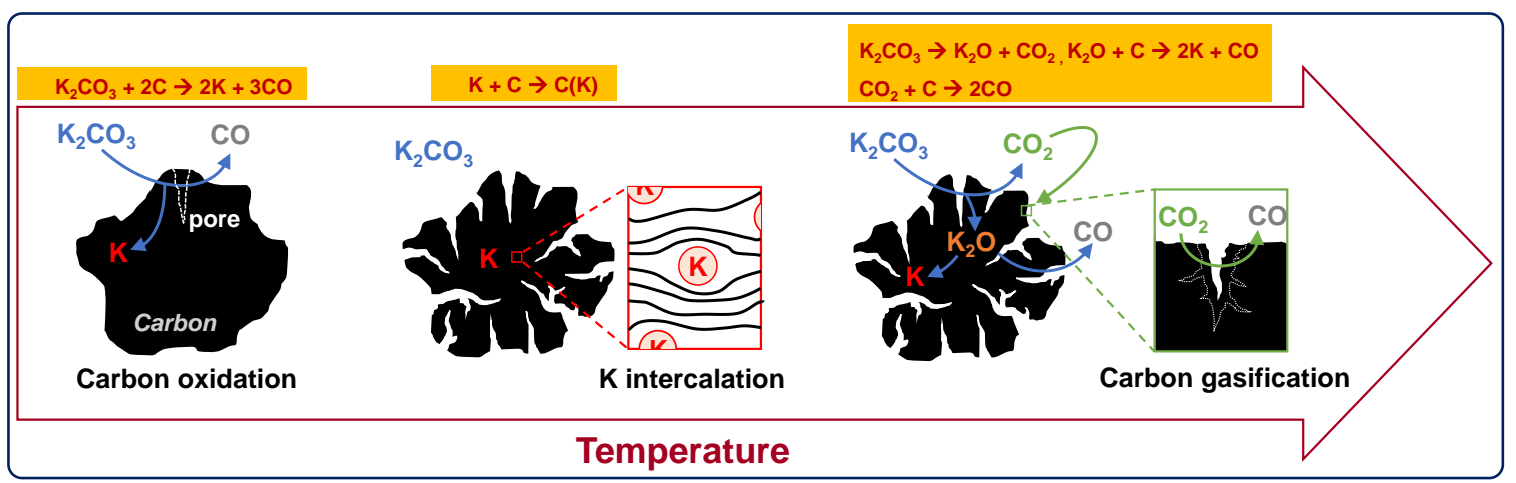

Figure 2. Schematic illustration of the pore generation mechanism corresponding to $\mathrm{K}_{2} \mathrm{CO}_{3}$.

As a result, the materials obtained by $\mathrm{K}_{2} \mathrm{CO}_{3}$ activation are normally rich in micropores with a limited amount of small mesopores. On the other hand, the inorganic matter remaining in the solid product after the activation process is un-reacted $\mathrm{K}_{2} \mathrm{CO}_{3}$ (or a hydrated phase owing to the contact with ambient air), which is normally removed by washing with diluted acid. The emitted gases are 
similar to those of a carbonization process (i.e., $\mathrm{CO}_{2}, \mathrm{CO}, \mathrm{H}_{2} \mathrm{O}, \mathrm{H}_{2}, \mathrm{CH}_{4}$, etc.), although in different proportions. ${ }^{[38]}$ It is important to note that reaction (1) takes place at temperatures higher than $600-700^{\circ} \mathrm{C},{ }^{[34,37]}$ whereas the redox reaction with $\mathrm{KOH}$ starts at lower temperatures $\left(\sim 400^{\circ} \mathrm{C}\right),{ }^{[36,39]}$ which explains the lower pore development achieved with $\mathrm{K}_{2} \mathrm{CO}_{3}$ compared to $\mathrm{KOH}$ (see Table 1). ${ }^{[40-44]}$ Besides, as mentioned above, $\mathrm{K}_{2} \mathrm{CO}_{3}$ is one of the products during $\mathrm{KOH}$ activation, so that for $\mathrm{T}>600-700^{\circ} \mathrm{C}$, reactions (1) to (4) also take place during $\mathrm{KOH}$ activation, yielding additional pore development. However, $\mathrm{K}_{2} \mathrm{CO}_{3}$ has two important additional advantages over $\mathrm{KOH}$. Firstly, it allows the preservation of the morphology of the precursor (see Figures 3a-b). ${ }^{[37,40]}$ Secondly, it has a catalytic action on the carbonization of biomass products, promoting the hydrolysis and de-polymerization reactions of cellulose and hemicellulose components [34] and the dehydration and polymerization reactions of monosaccharides, ${ }^{[45]}$ which increases the carbon yield, similarly to other more toxic chemical activating agents, such as $\mathrm{ZnCl}_{2}{ }^{[46]}$ and $\mathrm{H}_{3} \mathrm{PO}_{4}{ }^{[47]}$ This is very important from the industrial production point of view.

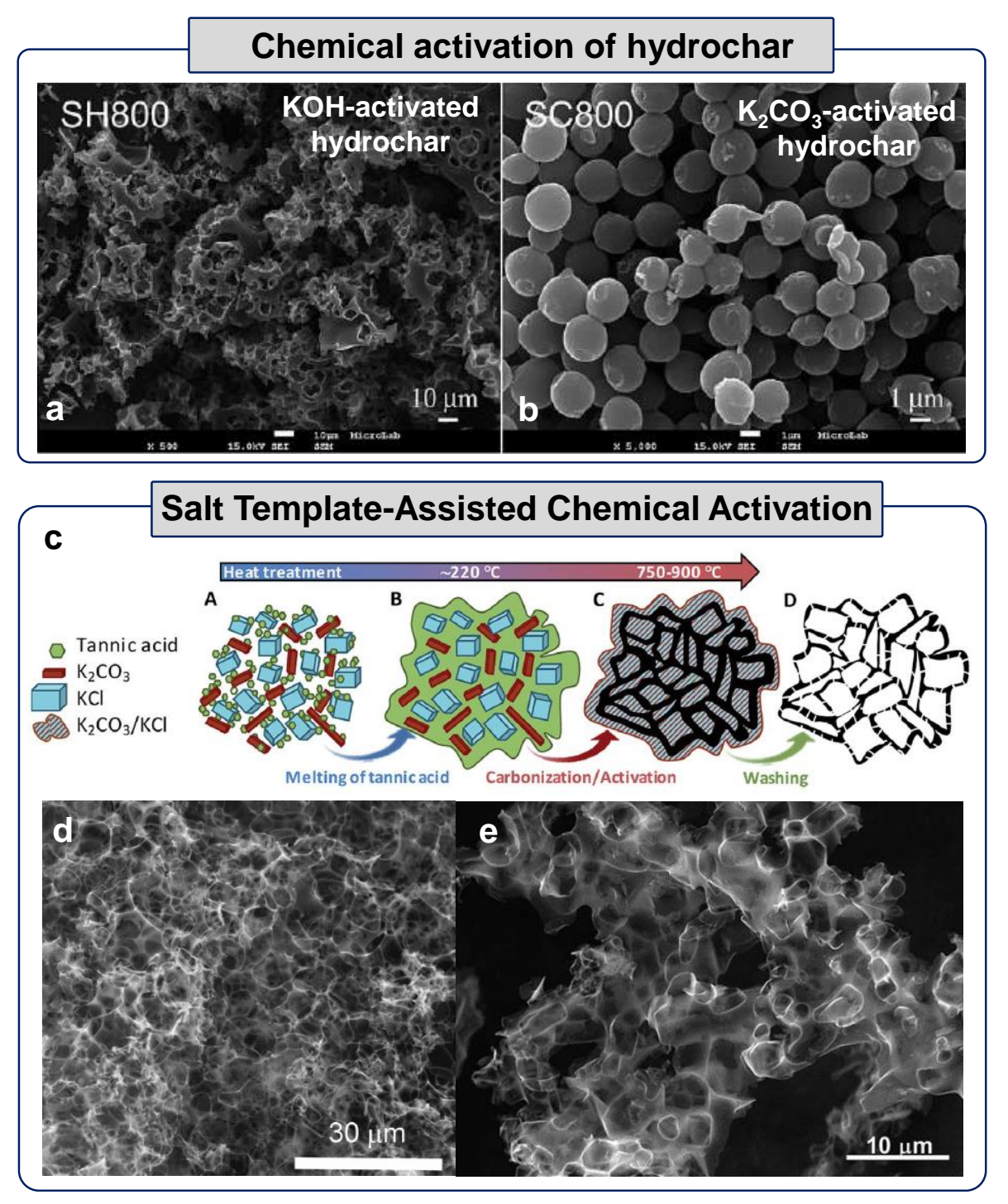

Figure 3. SEM pictures of a) $\mathrm{KOH}$-activated and b) $\mathrm{K}_{2} \mathrm{CO}_{3}$-activated hydrochar (Reproduced from ref. [40] with permission from the Royal Society of 
Chemistry). c) Illustration of the synthesis procedure of porous carbons by using a mixture of $\mathrm{K}_{2} \mathrm{CO}_{3}$ and $\mathrm{KCl}$. SEM pictures of (d) glucose and (e) tannic acidderived porous carbons prepared by a salt template-assisted chemical activation process (Reproduced from refs.[45,48] with permission from the Royal Society of Chemistry and Wiley-VCH).

Among all the examples available in the literature, we would like to highlight the work by Mestre et al., who compared the chemical activation of hydrothermally carbonized biomass, i.e. hydrochar, at $800{ }^{\circ} \mathrm{C}$ with $\mathrm{K}_{2} \mathrm{CO}_{3}$ and $\mathrm{KOH}$ (activating agent/hydrochar weight ratio $=4$ ). ${ }^{[40]} \mathrm{A}$ microporous carbon with a surface area of $\sim 1400 \mathrm{~m}^{2} \mathrm{~g}^{-1}$ and a pore volume of $0.63 \mathrm{~cm}^{3} \mathrm{~g}^{-1}$ was obtained with $\mathrm{K}_{2} \mathrm{CO}_{3}$ (Table 1), compared to values of $2430 \mathrm{~m}^{2} \mathrm{~g}^{-1}$ and $1.14 \mathrm{~cm}^{3}$ $\mathrm{g}^{-1}$ for the porous carbon fabricated with $\mathrm{KOH}$. However, the typical spherical morphology of sucrose-derived hydrochar was preserved when $\mathrm{K}_{2} \mathrm{CO}_{3}$ was used, whereas $\mathrm{KOH}$ completely destroyed the particle morphology (see Figures $3 a-b)$. This is important since a spherical morphology leads to better packing properties and reduced ion diffusion distances. Thus, the packing density of the materials was determined to be 0.79 and $0.36 \mathrm{~g} \mathrm{~cm}^{-3}$ for the $\mathrm{K}_{2} \mathrm{CO}_{3}$ - and the $\mathrm{KOH}$-derived ACs, respectively. This much higher packing density of the $\mathrm{K}_{2} \mathrm{CO}_{3}$-derived $\mathrm{AC}$ is not only explained by its lower pore development, but also by the particle morphology, since the particle density of the materials is 0.89 and $0.61 \mathrm{~g} \mathrm{~cm}^{-3}$ for the $\mathrm{K}_{2} \mathrm{CO}_{3}$ - and the $\mathrm{KOH}$-derived $\mathrm{ACs}$, respectively.

Recently, our group showed that the rational design of the activation procedure with $\mathrm{K}_{2} \mathrm{CO}_{3}$ can lead to materials with a pore development similar to that of benchmark $\mathrm{KOH}$-derived ACs. ${ }^{[4,48]}$ The synthesis procedure is illustrated in Figure 3c. By adding $\mathrm{KCl}$ as a reaction medium, the reactivity between the carbon and $\mathrm{K}_{2} \mathrm{CO}_{3}$ is greatly enhanced as a consequence of the presence of a melted phase of $\mathrm{KCl}+\mathrm{K}_{2} \mathrm{CO}_{3}$ for $\mathrm{T}>631^{\circ} \mathrm{C}$. In this way, materials with BET surface areas of up to ca. $2800 \mathrm{~m}^{2} \mathrm{~g}^{-1}$ and pore volumes of up to $1.42 \mathrm{~cm}^{3} \mathrm{~g}^{-1}$ are obtained from a variety of biomass-based products (i.e. tannic acid, glucose and soybean meal) (see Table 1). At the same time, the carbon yield is increased owing to the confined space provided by the melted $\mathrm{KCl}-\mathrm{K}_{2} \mathrm{CO}_{3}$ mixture. This increase is, for example, $2 \%$ in the case of glucose and soybean meal compared to the sole use of $\mathrm{K}_{2} \mathrm{CO}_{3}$ (for an increase in the pore volume of $40 \%$, and as high as $10 \%$ in the case of tannic acid compared to its simple carbonization. Additionally, $\mathrm{KCl}$ plays a second role as a template, leading to materials with a 3D sponge-like morphology (see Figures $3 d-e$ ). It must be highlighted that, in contrast to the use of solely $\mathrm{K}_{2} \mathrm{CO}_{3}$ or $\mathrm{KOH}$, in this synthesis strategy $\mathrm{KCl}$ and un-reacted $\mathrm{K}_{2} \mathrm{CO}_{3}$ can be removed by simply using water, which is an additional environmental benefit.

It is also worth highlighting the effect on pore development of adding an $\mathrm{N}$-rich compound, such as urea or melamine, to the mixture of $\mathrm{K}_{2} \mathrm{CO}_{3}$ and carbon precursor (besides causing $\mathrm{N}$-doping). In this regard, Tsubouchi et al. showed that the pyrolysis at $800-900^{\circ} \mathrm{C}$ of a mixture of carbon precursor (lignin), urea and $\mathrm{K}_{2} \mathrm{CO}_{3}$ leads to materials with ultrahigh pore development and increased mesopore volume, with BET surface areas as high as $3300-3400 \mathrm{~m}^{2}$ $\mathrm{g}^{-1}$ and pore volumes of $2.2-2.3 \mathrm{~cm}^{3} \mathrm{~g}^{-1}$. ${ }^{[49]}$ In contrast, activation of lignin with $\mathrm{K}_{2} \mathrm{CO}_{3}$ produces a material with BET surface area below $600 \mathrm{~m}^{2} \mathrm{~g}^{-1}$ and pore volume up to $\sim 0.3 \mathrm{~cm}^{3} \mathrm{~g}^{-1}$. Similar results were previously reported by our group by using mixtures of hydrochar, melamine and $\mathrm{KOH},{ }^{[50,51]}$ and more 
recently by Schneidermann et al. using mixtures of biomass/biomass derivatives, urea/melamine and $\mathrm{K}_{2} \mathrm{CO}_{3} \cdot{ }^{[52,53]}$ Tsubouchi et al. provided mechanistic insights for those results. They observed that when the lignin+urea $+\mathrm{K}_{2} \mathrm{CO}_{3}$ mixture is pyrolyzed, potassium cyanate $(\mathrm{KOCN})$ is already present at $200 \stackrel{\circ}{\circ}$. It may be formed through the following reactions:

$\mathrm{CH}_{4} \mathrm{~N}_{2} \mathrm{O}+0.5 \mathrm{~K}_{2} \mathrm{CO}_{3} \rightarrow \mathrm{KOCN}+0.5\left(\mathrm{CH}_{8} \mathrm{~N}_{2} \mathrm{O}_{3}\right)$

$\mathrm{K}_{2} \mathrm{CO}_{3}+\mathrm{C}-\mathrm{N} \rightarrow \mathrm{KOCN}+-\mathrm{CO}_{2} \mathrm{~K}$

$-\mathrm{CO}_{2} \mathrm{~K}+\mathrm{C}-\mathrm{N} \rightarrow \mathrm{KOCN}+\mathrm{CO}$

where $\mathrm{C}-\mathrm{N}$ sites correspond to nitrogen bonded to carbon in the char (formed as a consequence of secondary reactions between radical species generated in the decomposition of urea and edge carbons in the char). For temperatures higher than $700 \stackrel{\circ}{\circ}$, KOCN completely disappears and potassium cyanide (KCN) appears, which suggests the oxidation of carbon by potassium cyanate according to the reaction:

$\mathrm{KOCN}+\mathrm{C} \rightarrow \mathrm{KCN}+\mathrm{CO}$

It can therefore be assumed that this redox reaction along with the cleavage of $\mathrm{C}-\mathrm{N}$ bonds within the carbon matrix by $\mathrm{K}$-species produces a disorderly arrangement of microcrystals with larger gaps between them, which increases the specific surface area. ${ }^{[49]}$ This also explains the production of porous carbons with outstanding pore development and a micro-/mesoporous pore network when carbon precursors with a high nitrogen content (i.e., polypyrrole) are chemically activated with $\mathrm{KOH}^{[22,54,55]}$ Likewise, it explains the preferential removal of nitrogen species contained in the carbon precursor/char during chemical activation with $\mathrm{K}$-based salts. At this point, it must be noted that potassium cyanide is highly toxic and this speaks against the suitability of these pore generation strategies based on $\mathrm{N}$-rich foreign additives and $\mathrm{K}$-based salts. When an N-rich carbon precursor is used, $\mathrm{KCN}$ is also formed, but in a much lower amount. In this kind of activations mediated by N-rich compounds, the emitted gases contain toxic $\mathrm{N}$-species such as $\mathrm{NH}_{3}$. However, the amount generated is smaller than during the carbonization of biomass and the N-rich additive, since most nitrogen is retained in the solid product (i.e., $\mathrm{N}$-doped carbon and $\mathrm{KCN}) .{ }^{[49]}$

As evidenced by Figure 1, an even milder potassium salt than potassium carbonate -and then appealing from the environmental point of view- is potassium bicarbonate. In a pioneering study, Deng et al. showed that the chemical activation of a variety of biomass products (e.g., cellulose, chitin and bamboo) with $\mathrm{KHCO}_{3}$ leads to carbon materials with a 3D hierarchical pore structure, comprising micropores, mesopores and macropores (see Figure 4a). ${ }^{[56]}$ To produce such a structure, they were inspired by the bread-making process and selected a gas-producing chemical substance such as $\mathrm{KHCO}_{3}$. $\mathrm{KHCO}_{3}$ decomposes at around $200 \stackrel{\circ}{\circ}$, according to:

$2 \mathrm{KHCO}_{3} \rightarrow \mathrm{K}_{2} \mathrm{CO}_{3}+\mathrm{CO}_{2}+\mathrm{H}_{2} \mathrm{O}$

The $\mathrm{CO}_{2}$ thus generated dilated and produced the macropores (see Figure 4b), while the micro- and mesopores were generated by the reaction between $\mathrm{K}_{2} \mathrm{CO}_{3}$ and the carbonaceous matter according to reactions (1) to (4). These materials exhibited BET surface areas up to ca. $1900 \mathrm{~m}^{2} \mathrm{~g}^{-1}$ depending on the carbon precursor and activation conditions (see Table 1) and a bulk density as 
low as $0.043 \mathrm{~g} \mathrm{~cm}^{-3}$ (porosity of $85 \%$ ). By increasing the $\mathrm{KHCO}_{3} /$ cellulose weight ratio from 2 to 6 , it was possible to increase the specific surface area from $1693 \mathrm{~m}^{2} \mathrm{~g}^{-1}$ to $1893 \mathrm{~m}^{2} \mathrm{~g}^{-1}$. However, at a higher ratio of 8 the surface area decreased to $1709 \mathrm{~m}^{2} \mathrm{~g}^{-1}$, which may be due to some pore collapse as a consequence of excessive activation. It should be noted that the carbon yield of the process is not very high, of around $6-10 \%$ for a $\mathrm{KHCO}_{3} /$ precursor weight ratio $=4$ (see Table 1). Since this study, $\mathrm{KHCO}_{3}$ activation has been applied to a variety of precursors, including not only biomass, ${ }^{[57-66]}$ but also biochar ${ }^{[43,67-}$ ${ }^{69]}$ and hydrochar, ${ }^{[37,70-72]}$ for use in a variety of applications, as compiled in Table 1.

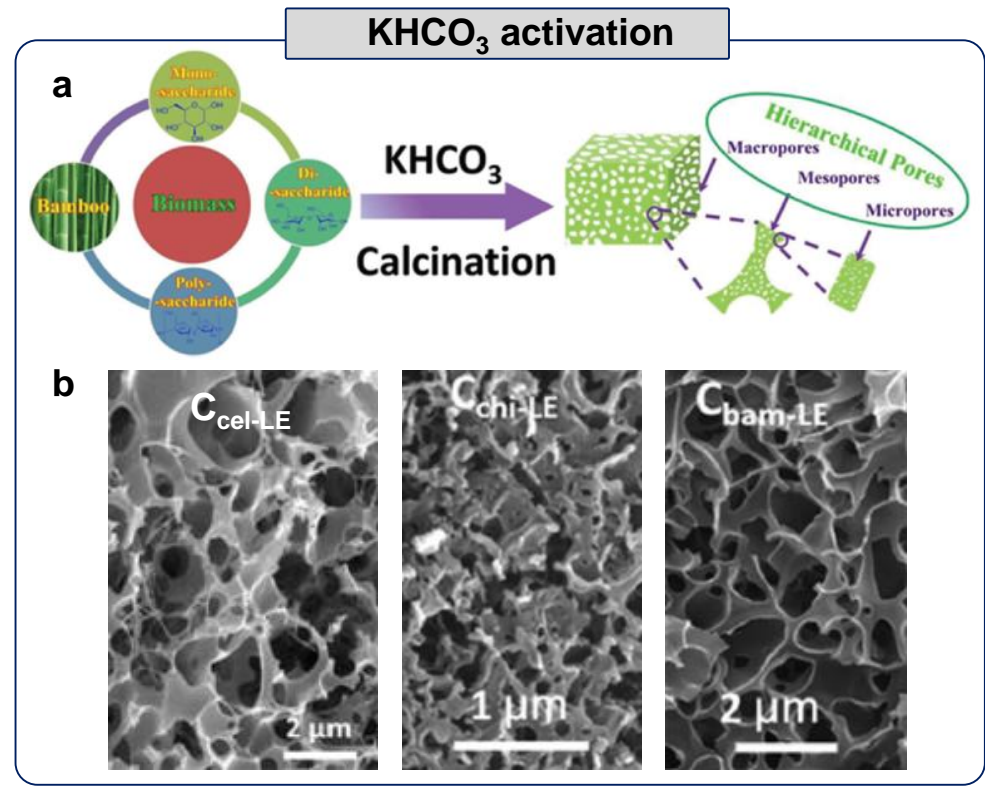

Figure 4. a) Schematic diagram of the formation of porous carbons by using $\mathrm{KHCO}_{3}$ as activating agent, b) SEM pictures of the porous carbons derived from cellulose $\left(\mathrm{C}_{\text {cel-LE}}\right)$, chitin $\left(\mathrm{C}_{\text {chi-LE }}\right)$ and bamboo $\left(\mathrm{C}_{\text {bam-LEE }}\right)$ (Reproduced from ref. [56] with permission from the Royal Society of Chemistry).

Similarly to $\mathrm{K}_{2} \mathrm{CO}_{3}$, our group has shown that $\mathrm{KHCO}_{3}$ also allows the preservation of the morphology of hydrochar precursors, whose consolidated structure is not affected by the $\mathrm{CO}_{2}$ evolved in the decomposition of $\mathrm{KHCO}_{3} \cdot{ }^{\left[{ }^{[3]}\right]}$ In this way, porous carbons made up of microspheres with surface areas in the 2000-2300 $\mathrm{m} \mathrm{g}^{-1}$ range were obtained (Table 1). Similar to the case of cellulose above described, an increase of the $\mathrm{KHCO}_{3}$ /hydrochar ratio from 4 to 6 enhances the pore development ( $S_{\text {BET }}$ increases from 1996 to $2230 \mathrm{~m}^{2} \mathrm{~g}^{-1}$ and $V_{p}$ from 0.87 to $1.05 \mathrm{~cm}^{3} \mathrm{~g}^{-1}$ ) and causes certain rise in mesoporosity (the \% of pore volume corresponding to mesopores rises from 13 to $20 \%$ ). However, further increase of the $\mathrm{KHCO}_{3}$ /hydrochar ratio to 8 causes some pore collapse, the pore volume decreasing to $0.89 \mathrm{~cm}^{3} \mathrm{~g}^{-1}$. The materials were mainly microporous, although some small mesopores could be introduced by lengthening the residence time at $850^{\circ} \mathrm{C}$, as a consequence of reactions (2) to (4) taking place. To further enhance mesopore development in the $\mathrm{KHCO}_{3}-\mathrm{ACs}$, melamine was added to the $\mathrm{HKCO}_{3} /$ hydrochar mixture used in the activation process. In this way, a porous carbon with an ultra-large BET surface area and 
pore volume was obtained (see Table 1), with a pore size distribution exhibiting maxima at $\sim 0.9$ and $2.3 \mathrm{~nm}$ and a $\mathrm{V}_{\text {microp }} / \mathrm{V}_{\text {mesop }} \sim 0.84$. In addition, a nitrogen content of $\sim 4.2 \mathrm{wt} \%$ was measured. Importantly, a $10 \%$ increase in the carbon yield of the final product was registered when using $\mathrm{KHCO}_{3}$ instead of $\mathrm{KOH}$.

In contrast to potassium-based carbonates and bicarbonates, their sodium-based counterparts have hardly been used as activating agents, as they are less effective (Table 1). ${ }^{[64,73-78]}$ This may be explained by the lower catalytic activity of the sodium carbonates for carbon gasification. ${ }^{[4,79]}$ The porogenic action of $\mathrm{Na}_{2} \mathrm{CO}_{3}$ (or any alkali metal carbonate) is based on the same redox reaction as in the case of $\mathrm{K}_{2} \mathrm{CO}_{3}$ :

$\mathrm{Na}_{2} \mathrm{CO}_{3}+2 \mathrm{C} \rightarrow 2 \mathrm{Na}+3 \mathrm{CO}$

which can be inferred by the presence of metallic sodium in the cool parts of the reactor. However, $\mathrm{Na}_{2} \mathrm{CO}_{3}$ decomposes only at temperatures higher than $1000^{\circ} \mathrm{C},{ }^{[80]}$ so that reactions equivalent to (2) to (4) but based on $\mathrm{Na}$ do not take place in the case of $\mathrm{Na}_{2} \mathrm{CO}_{3}$. As an example, Fujiki and Yogo analyzed the activation of chitosan by using a variety of alkali metal carbonates (i.e., $\mathrm{Na}_{2} \mathrm{CO}_{3}$, $\mathrm{K}_{2} \mathrm{CO}_{3}, \mathrm{Rb}_{2} \mathrm{CO}_{3}$ or $\mathrm{Cs}_{2} \mathrm{CO}_{3}$ ) in the temperature range from 500 to $700{ }^{\circ} \mathrm{C}$. ${ }^{[74]}$ The highest pore development was achieved at $700{ }^{\circ} \mathrm{C}$ for all the carbonates except for $\mathrm{Cs}_{2} \mathrm{CO}_{3}$, which showed the largest values of surface area and pore volume (respectively, $1530 \mathrm{~m}^{2} \mathrm{~g}^{-1}$ and $0.78 \mathrm{~cm}^{3} \mathrm{~g}^{-1}$ ) at $600{ }^{\circ} \mathrm{C}$. This work clearly demonstrates the lesser effectiveness of $\mathrm{Na}_{2} \mathrm{CO}_{3}$ as an activating agent, which leads to a maximum surface area value of $1328 \mathrm{~m}^{2} \mathrm{~g}^{-1} \mathrm{vs} .2045$ and $2145 \mathrm{~m}^{2} \mathrm{~g}^{-1}$ for $\mathrm{K}_{2} \mathrm{CO}_{3}$ and $\mathrm{Rb}_{2} \mathrm{CO}_{3}$ at $700^{\circ} \mathrm{C}$, respectively (Table 1 ).

With regards to the use of $\mathrm{NaHCO}_{3}$ as activating agent, Tian et al. explored the activation of a mixture of glucose and thiourea. ${ }^{[76]}$ Thiourea not only caused $\mathrm{N}$ - and S-codoping of the carbon materials obtained (see Table 1), but also some pore generation and enhancement of the BET surface area (the mechanism for pore generation is presumably similar to that of $\mathrm{K}$-based salts with urea, as $\mathrm{Na}$ also readily reacts with $\mathrm{N}$-containing compounds generating $\mathrm{NaOCN}){ }^{[81]}$ Similarly to the case of $\mathrm{KHCO}_{3}$, materials with a hierarchical micro/meso/macroporous structure were obtained, albeit with a lower pore development (see Table 1).

\subsection{Alkali metal organic salts}

Organic salts comprising an alkali metal, such as sodium or potassium, and an organic part can be used as self-activators when the carbon yield is satisfactory (see Section 3 for a deeper discussion) or as activating agents when the organic part is completely decomposed during the pyrolysis process. In this latter case, only the corresponding carbonate remains, this being the actual activating agent. This is the case of potassium oxalate, whose toxicity is similar to that of $\mathrm{K}_{2} \mathrm{CO}_{3}$ and lower than that of traditional activating agents (Figure 1). When potassium oxalate is pyrolyzed, it decomposes in the temperature range of $500-600 \stackrel{\circ}{\mathrm{C}}$ according to:

$\mathrm{K}_{2} \mathrm{C}_{2} \mathrm{O}_{4} \rightarrow \mathrm{K}_{2} \mathrm{CO}_{3}+\mathrm{CO}$

yielding no carbon residue. ${ }^{[82,83]}$ The $\mathrm{K}_{2} \mathrm{CO}_{3}$ thus generated can then react with the carbonaceous matter at $\mathrm{T}>700^{\circ} \mathrm{C}$ following reaction (1) (see Section 2.1), causing the partial etching of carbon atoms under controlled activation 
conditions. For higher temperatures, reactions (2) to (4) can also proceed (see Section 2.1), creating additional porosity or enlarging the existing pores. The textural properties of the materials derived from potassium oxalate are therefore similar to those of potassium carbonates/bicarbonates, i.e. highly microporous carbons with some small mesopores and BET surface areas normally of up to around $2000 \mathrm{~m}^{2} \mathrm{~g}^{-1}$ (Table 1). ${ }^{\left[{ }^{83-87]}\right.}$ It is worth noting that potassium oxalate melts at a low temperature of $390{ }^{\circ} \mathrm{C}$, inducing a sheet-like morphology in carbons derived from melting precursors such as glucose or sucrose (Figure 5a). ${ }^{[83,87]}$ However, when non-melting precursors are used, such as hydrochar (Figure $5 b)^{[82,83,88]}$ or seeds (Figure $5 c$ ) ${ }^{[85]}$ the morphology is preserved in the same way as with carbonates/bicarbonates. In addition, it has been shown that the yield of the activation process in the case of saccharides is as high as 23-30 $\%$ (i.e., $30-50 \%$ higher than their simple carbonization). This is due to the fact that potassium oxalate catalyzes the dehydration and polymerization reactions that take place during the initial stages of the carbonization process. ${ }^{[83]}$

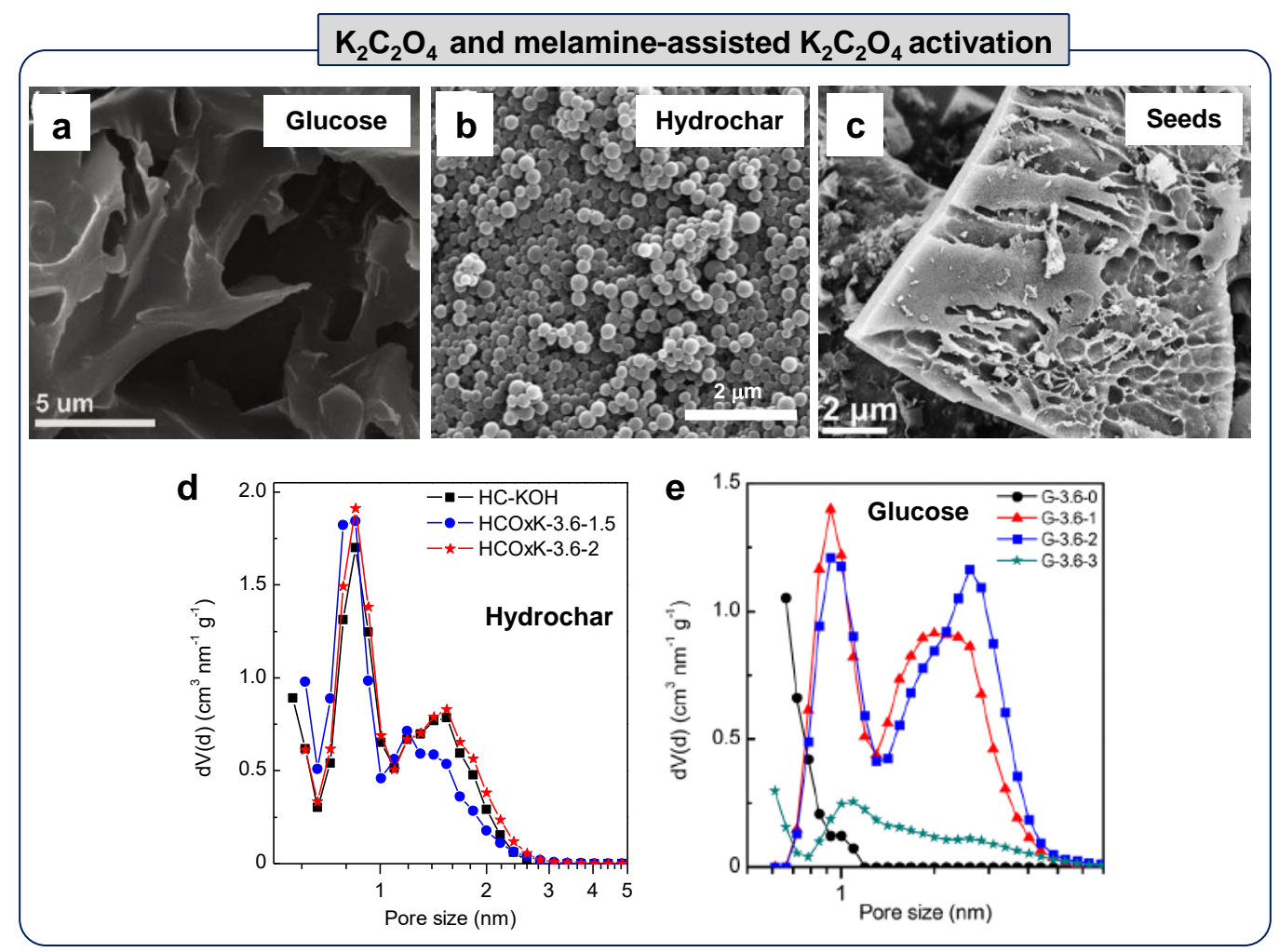

Figure 5. SEM images of the ACs produced by $\mathrm{K}_{2} \mathrm{C}_{2} \mathrm{O}_{4}$ activation using as precursor a) glucose (Reproduced with permission from ref. [87]. Copyright 2019, Elsevier, Ltd), b) glucose-derived hydrochar (Reproduced with permission from ref. [83]. Copyright 2018, American Chemical Society) and c) seeds (Reproduced from ref. [85] with permission from the Royal Society of Chemistry). Pore size distributions of the $\left(\mathrm{K}_{2} \mathrm{C}_{2} \mathrm{O}_{4}+\right.$ melamine)-derived $\mathrm{ACs}$ produced from d) hydrochar and e) glucose (Reproduced with permission from ref. [83]. Copyright 2018, American Chemical Society).

Interestingly, our group has shown that, when hydrochar is used as a carbon precursor, the mixture of potassium oxalate and melamine allows the production of highly microporous carbons with textural properties that mimic 
those of superactivated carbons prepared by $\mathrm{KOH}$ activation, i.e. BET surface areas of 2600-3000 $\mathrm{m}^{2} \mathrm{~g}^{-1}$, pore volumes of $\sim 1.3-1.6 \mathrm{~cm}^{3} \mathrm{~g}^{-1}$ and pore size distributions in the supermicropore-small mesopore $(<3 \mathrm{~nm}$ ) region (see Figure $5 d$ ). Importantly, the carbon yield is almost twice that of $\mathrm{KOH}$ activation (see Table 1). ${ }^{[82]}$ We studied the mechanism of porous carbon formation by TGA, FTIR, XRD and $\mathrm{N}_{2}$ physisorption, and showed that (besides the formation of $\mathrm{KOCN} / \mathrm{KCN}$ as in the case of urea) a poorly polymerized carbon nitride is formed from melamine, its decomposition already causing substantial pore development at $500{ }^{\circ} \mathrm{C}$. A further increase in temperature to $750{ }^{\circ} \mathrm{C}$, the temperature at which reactions (1) and (8) take place (see Section 2.1), promoted the development of a high porosity and an increase in pore size. Although this type of procedure may initially seem benign, the generation of $\mathrm{KCN}$ as a by-product must always be examined and taken into consideration. On the other hand, we showed that when saccharides are used as a carbon precursor instead of hydrochar, the mixture of potassium oxalate and melamine leads to highly micro-mesoporous carbons with BET surface areas as large as $3500 \mathrm{~m}^{2} \mathrm{~g}^{-1}$ and pore volumes up to $2.72 \mathrm{~cm}^{3} \mathrm{~g}^{-1}$, the ratio of micropore to mesopore volume being of $\sim 0.6-0.9$ (Figure $5 \mathrm{e}$ ). ${ }^{[83]}$ These results are similar to those of mixtures of carbon precursor, urea/melamine and $\mathrm{KOH}, \mathrm{K}_{2} \mathrm{CO}_{3}$ or $\mathrm{KHCO}_{3}$ (see Section 2.1). In addition, the materials are $\mathrm{N}$-doped, with $\mathrm{N}$ content ranging from 1 to $20 \mathrm{wt} \%$ depending on the synthesis conditions (Table 1). In the case of using lignocellulosic biomass such as eucalyptus sawdust, an intermediate situation between that of saccharides and hydrochar was observed, which was attributed to a higher resistance (lower reactivity) of lignin (and hydrochar) to the activating mixture potassium oxalate + melamine owing to its higher degree of aromatization compared to saccharides.

Taking one step forward, we combined the use of potassium oxalate as an activating agent and calcium carbonate nanoparticles as a hard template to produce, in a one-pot scheme, hierarchical porous carbons from biomass ${ }^{[89]}$ We found that, during carbonization, double carbonates $\left(\mathrm{K}_{2} \mathrm{Ca}\left(\mathrm{CO}_{3}\right)_{2}\right.$ and $\left.\mathrm{K}_{2} \mathrm{Ca}_{2}\left(\mathrm{CO}_{3}\right)_{3}\right)$ were formed in situ, which resulted in modifications in the morphology and size of the template nanoparticles. This gave rise to a carbon material with an open macroporous foam-like structure rich in micro-/mesopores (see Figures 6a,b), the latter developing via reaction (1) described in Section 2.1 and also as a result of the reaction between the carbon and the $\mathrm{CO}_{2}$ evolved in various reactions. The final inorganic impurities present in the porous carbon are $\mathrm{CaO}$ and $\mathrm{K}_{2} \mathrm{CO}_{3}$, which can be easily removed by washing with diluted $\mathrm{HCl}$. The pore structure of the materials produced could be tailored by selecting an appropriate carbon precursor. Thus, a direct relationship was observed between the amount of nitrogen present in the precursor and mesopore development (Figure 6c). Hence, the addition of urea to the mixture of glucose and potassium oxalate and $\mathrm{CaCO}_{3}$ nanoparticles also yielded micro/meso-/macroporous carbons (Figure 6d). These results further confirm the essential role that nitrogen heteroatoms have on porosity development, regardless of whether they come from a foreign additive (e.g., melamine or urea) or they form part of the carbon precursor. The materials synthesized at $750{ }^{\circ} \mathrm{C}$ from $\mathrm{N}$-rich biomass or glucose+urea combined ultra-large surface areas of $2400-3200 \mathrm{~m}^{2} \mathrm{~g}^{-1}$ and notable N-doping (2-3 wt \% N) (see Table 1). Very recently, $\mathrm{Li}$ et al. followed this same strategy, also producing hierarchical porous carbons from cornstalk without pith (Table 1). ${ }^{[86]}$ 


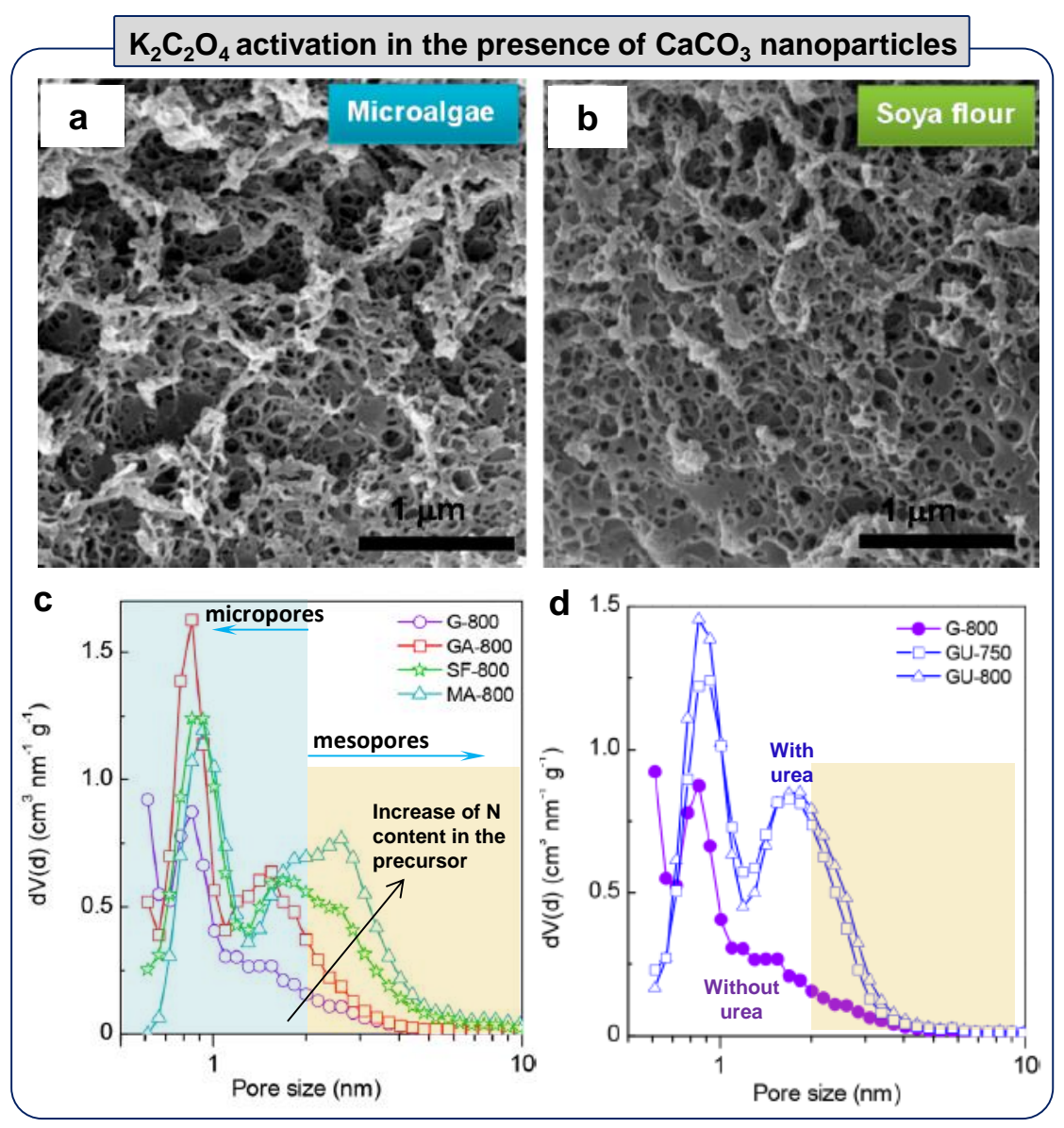

Figure 6. SEM images of the hierarchical porous carbons produced by $\mathrm{K}_{2} \mathrm{C}_{2} \mathrm{O}_{4}$ activation in the presence of $\mathrm{CaCO}_{3}$ nanoparticles using as carbon precursor a) microalgae and b) soya flour. Pore size distributions of the hierarchical porous carbons produced from c) a variety of carbon precursors and d) with and without the addition of urea to glucose (Adapted with permission from ref. ${ }^{[89]}$. Copyright 2017, American Chemical Society).

Another frequently used organic salt, with lower health hazards than potassium carbonate and oxalate (Figure 1), is potassium acetate. In this case, the materials produced are also microporous carbons with BET surface areas up to $\sim 1900 \mathrm{~m}^{2} \mathrm{~g}^{-1}$ and pore volumes up to $\sim 0.9 \mathrm{~cm}^{3} \mathrm{~g}^{-1}$, depending on the activation conditions and the carbon precursor (Table 1). ${ }^{[0}$

Although sodium and potassium citrates $\left(\mathrm{Na}_{3} \mathrm{C}_{6} \mathrm{H}_{5} \mathrm{O}_{7}\right.$ and $\mathrm{K}_{3} \mathrm{C}_{6} \mathrm{H}_{5} \mathrm{O}_{7}$, respectively) yield substantial carbon residue and therefore can be used as selfactivators as will be described in detail in Section 3, some researchers have also used them as activating agents, employing another main carbon source. The carbon materials thus produced are micro-macroporous with BET surface areas below $2000 \mathrm{~m}^{2} \mathrm{~g}^{-1}$ and pore volumes up to around $1 \mathrm{~cm}^{3} \mathrm{~g}^{-1}$ (see Table 1). ${ }^{[94-98]}$ In addition, potassium/sodium citrates have frequently been incorporated during the synthesis of resorcinol-formaldehyde resins, thus yielding porous carbons (see Table 1). ${ }^{[99-101]}$ 


\subsection{Alkali metal sulfates and thiosulfates}

Similarly to carbonates, sulfates are able to oxidize carbon at temperatures $>342 \stackrel{\circ}{-} \mathrm{C}$ according to:

$\mathrm{M}_{2} \mathrm{SO}_{4}+2 \mathrm{C} \rightarrow \mathrm{M}_{2} \mathrm{~S}+2 \mathrm{CO}_{2} \quad \mathrm{M}=\mathrm{Na}, \mathrm{K}$

And, at temperatures higher than $520^{\circ} \mathrm{C}$, the following reaction is also feasible:

$\mathrm{M}_{2} \mathrm{SO}_{4}+4 \mathrm{C} \rightarrow \mathrm{M}_{2} \mathrm{~S}+4 \mathrm{CO}$

When thiosulfates are used instead, they decompose at temperatures above $250 \stackrel{\circ}{\mathrm{C}}$ according to the reaction:

$4 \mathrm{M}_{2} \mathrm{~S}_{2} \mathrm{O}_{3} \rightarrow 3 \mathrm{M}_{2} \mathrm{SO}_{4}+\mathrm{M}_{2} \mathrm{~S}_{5}$

In this way, the sulfate generated becomes the only oxidizing agent able to react with the carbonaceous matter generating porosity according to reactions (12) and (13). As a result, the solid residue will be made up of unreacted porous carbon and $\mathrm{M}_{2} \mathrm{SO}_{4}$, and sodium/potassium sulfide/polysulfides, which can be easily eliminated by water washing. These sulfide/polysulfides can be easily re-oxidized by a simple $\mathrm{O}_{2}$ bubbling, giving rise to a solution containing the ingredient used for the synthesis of the carbon (i.e., $\mathrm{M}_{2} \mathrm{~S}_{2} \mathrm{O}_{3}$ ), which could then be recirculated to the activation system. ${ }^{[102,103]}$ Besides, vapors of elemental sulfur are also generated by the disproportionation of the polysulfides $\left(\mathrm{M}_{2} \mathrm{~S}_{5} \rightarrow \mathrm{M}_{2} \mathrm{~S}+4 \mathrm{~S}\right)$ and condense in the cold parts of the reactor; from an industrial production standpoint, it could be collected and recovered from downstream cooled filters.

It should be noted that the use of sodium/potassium sulfate/thiosulfate has hardly been described in the scientific literature despite being benign salts (see Figure 1), which may be because they normally produce materials with surface areas below $\sim 1000-1500 \mathrm{~m}^{2} \mathrm{~g}^{-1}$.102-104] However, Liu and Antonietti, ${ }^{[104,105]}$ and our group ${ }^{[102,103]}$ have developed novel approaches for the efficient production of high surface area porous carbons from sulfates/thiosulfates. Liu and Antonietti introduced a molten salt activation approach, in which $\mathrm{K}_{2} \mathrm{SO}_{4}$ is able to produce a microporous carbon from glucose with a BET surface area of $1520 \mathrm{~m}^{2} \mathrm{~g}^{-1}$ in a high carbon yield of $55 \%$ by using an eutectic mixture of $\mathrm{LiCl}$ and $\mathrm{KCl}$ (melting point $=353^{\circ} \mathrm{\circ}$ ) as reaction medium $\left(T=900{ }^{\circ} \mathrm{C}\right)\left(\right.$ Table 1)..$^{[105]}$ This molten salt activation approach is not only efficient in producing porous carbons, but also allows the controllable production of S-doped 2D carbon nanosheets (Figure 7a). Later on, these authors extended the approach to $\mathrm{Na}_{2} \mathrm{~S}_{2} \mathrm{O}_{3}$ in order to increase S-doping. By doing so, a porous material composed of nanosheets with surface area of 3250 $\mathrm{m}^{2} \mathrm{~g}^{-1}$ and $\mathrm{S}$ content of $\sim 4.8 \mathrm{wt} \%$ was synthesized at $900{ }^{\circ} \mathrm{C}$ (carbon yield $>25$ $\%$, Table 1). ${ }^{[104]}$ According to the authors, the high porosity of the carbons seemed to be the result of the cooperative interaction of the inert chloride salts and the reactive salts. More recently, our group has shown that materials with similar characteristics can be produced by simply mixing $\mathrm{Na}_{2} \mathrm{~S}_{2} \mathrm{O}_{3}$ and $\mathrm{KCl}^{[102,103]}$ This is due to the fact that the $\mathrm{Na}_{2} \mathrm{~S}$ formed according to reactions (12) and (13) forms a liquid phase at $\mathrm{T}>740{ }^{\circ} \mathrm{C}$ with the unreacted $\mathrm{Na}_{2} \mathrm{SO}_{4}$ (i.e., eutectic point at $28 \% \mathrm{~mol} \mathrm{Na}_{2} \mathrm{~S}$ ) and $\mathrm{KCl}$ also melts at $\sim 770 \stackrel{\circ}{\circ}$. Under these conditions, the melted $\mathrm{KCl}$ acts as a confinement medium which reinforces the contact between the solid carbonaceous matter and the $\mathrm{Na}_{2} \mathrm{SO}_{4}$ $\mathrm{Na}_{2} \mathrm{~S}$ liquid system, enhancing the reactivity (see Figure $7 \mathrm{~b}$ ). Thereby, highly 
porous carbons with BET surface areas up to $\sim 2700 \mathrm{~m}^{2} \mathrm{~g}^{-1}$ were produced from biomass and biomass-derivatives (Table 1). It is worth highlighting that these porous carbons were obtained by using considerably lower ratios of activating agent to precursor $(<1.5)$ than those used in $\mathrm{KOH}$ activation (usually $\sim 4$ ) and, in contrast to $\mathrm{KOH}$, there is no need for an acid to remove the inorganic salts. Furthermore, high carbon yields in the $11-20 \mathrm{wt} \%$ can be obtained by the confinement effect of $\mathrm{KCl}$, while direct $\mathrm{KOH}$ activation of biomass leads to considerably lower carbon yields and sometimes even to its complete consumption. In this case, depending on whether the carbon precursor melts (e.g., tannic acid or glucose) or not (e.g., eucalyptus sawdust), the porous carbon particles present a foam-like structure as a result of the templating effect of $\mathrm{KCl}$ and $\mathrm{Na}_{2} \mathrm{SO}_{4}$ solid particles at low temperatures (Figure 7c) or retain the typical structure of the precursor (Figure 7d). Besides that, the materials are basically composed of narrow micropores for $\mathrm{Na}_{2} \mathrm{~S}_{2} \mathrm{O}_{3}$ /precursor weight ratios $\leq 1$, while there is a notable increase in the proportion of large micropores $(1-2 \mathrm{~nm})$ and also of small mesopores $(\sim 2-5 \mathrm{~nm})$ for weight ratios above 1 . The general applicability of this strategy for the production of highly porous carbons has also been demonstrated by using a polymer such as polypyrrole ( $S_{\text {BET }}$ up to $\sim 2500 \mathrm{~m}^{2} \mathrm{~g}^{-1}$, see Table 1). ${ }^{[106,107]}$ Moreover, the polysulfides/sulfides generated during the activation step can be used for the insitu synthesis of sulfur nanoparticles confined within the porosity of the porous carbon and, in this way, the synthesis of sulfur/carbon composites for Li-S batteries. ${ }^{[106-108]}$ 


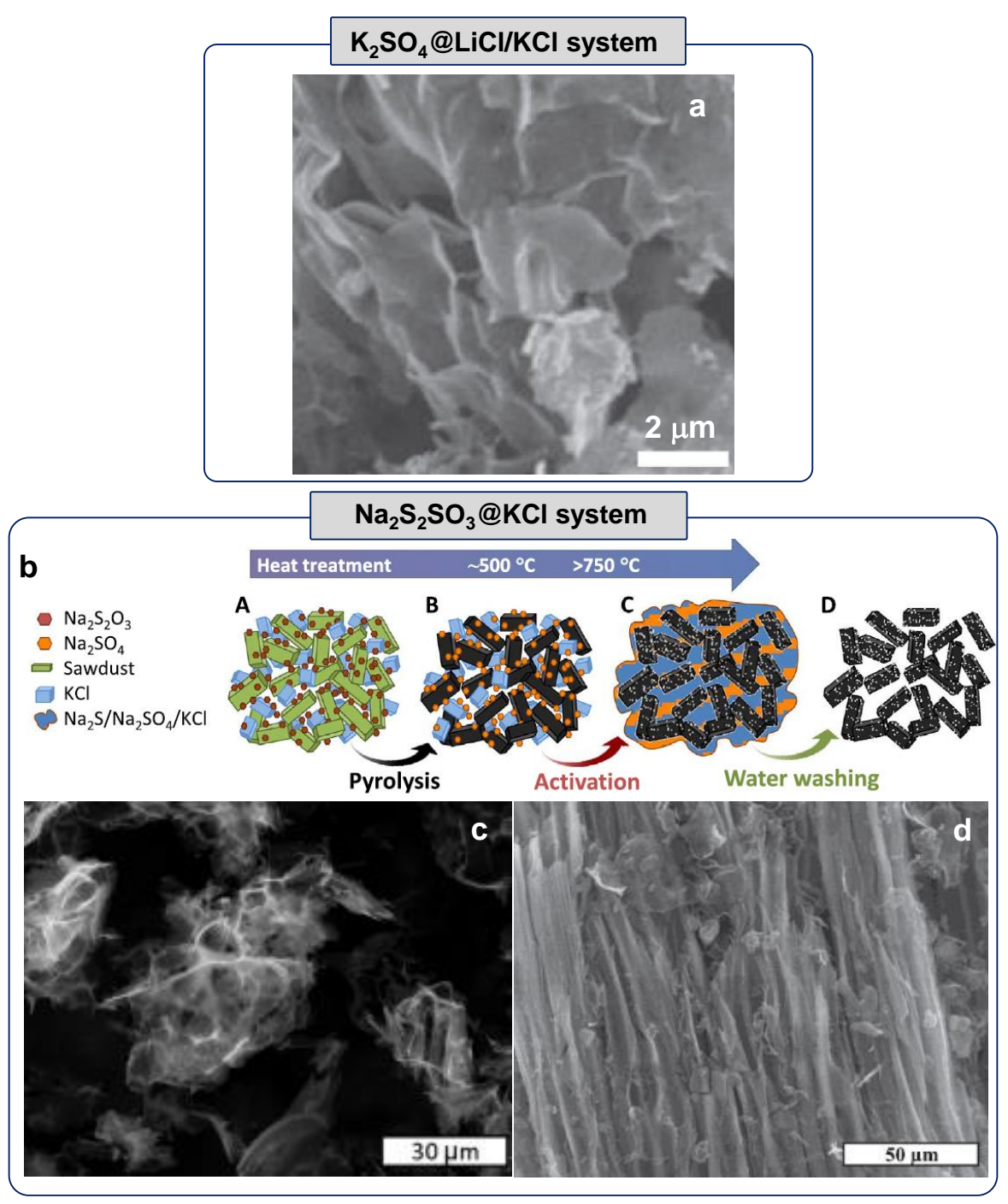

Figure 7. SEM image of the porous carbon produced in a $\mathrm{K}_{2} \mathrm{SO}_{4} @ \mathrm{LiCl} / \mathrm{KCl}$ system (carbon precursor: glucose) (Reproduced with permission from ref. [105]. Copyright 2014, Elsevier, Ltd). b) Schematic illustration of the synthesis procedure of porous carbons by using a $\mathrm{Na}_{2} \mathrm{~S}_{2} \mathrm{SO}_{3} / \mathrm{KCl}$ system (Reproduced with permission from ref. [102], Copyright 2019, Elsevier, Ltd). SEM images of the porous carbons produced in a $\mathrm{Na}_{2} \mathrm{~S}_{2} \mathrm{SO}_{3} / \mathrm{KCl}$ system using as carbon precursor c) glucose (Reproduced with permission from ref. [103]. Copyright 2018, American Chemical Society) and d) sawdust (Reproduced with permission from ref. [102], Copyright 2019, Elsevier, Ltd). 
Table 1. Summary of porous carbons produced by chemical activation with a variety of benign alkali metal salts. 


\begin{tabular}{|c|c|c|c|c|c|c|c|c|c|c|c|}
\hline $\begin{array}{l}\text { Activating } \\
\text { agent }\end{array}$ & $\begin{array}{l}\text { Carbon } \\
\text { precursor }\end{array}$ & $\begin{array}{c}\text { Mixing } \\
\text { procedure }\end{array}$ & Additives & $\begin{array}{l}\text { Doping } \\
(\%)^{\text {[a] }}\end{array}$ & $\begin{array}{c}T_{\text {pyrolysis }} \\
\left({ }^{\circ} \mathrm{C}\right)\end{array}$ & $\begin{array}{c}S_{B E T} \\
\left(m^{2} g^{-1}\right)\end{array}$ & $\begin{array}{c}\text { Pore } \\
\text { volume } \\
\left(\mathrm{cm}^{3} \mathbf{g}^{-1}\right)^{[\mathbf{b}]}\end{array}$ & $\begin{array}{c}\text { Pore } \\
\text { structure }^{[c]}\end{array}$ & $\begin{array}{l}\text { Carbon } \\
\text { yield } \\
(\%)^{[d]}\end{array}$ & Application & Reference \\
\hline \multirow{12}{*}{$\begin{array}{l}\text { Potassium } \\
\text { carbonate }\end{array}$} & Nutshells & Solution & - & - & $\begin{array}{l}500- \\
900\end{array}$ & $\sim 300-1800$ & $\sim 0.1-0.85$ & $\mathrm{Mi}$ & n.d. & - & [34] \\
\hline & Hydrochar & Solution & - & - & $\begin{array}{l}700- \\
800\end{array}$ & $\sim 700-1400$ & $0.3-0.6$ & $\mathrm{Mi}$ & $13-15^{[\mathrm{ee}]}$ & $\begin{array}{l}\mathrm{CH}_{4} \text { storage and landfill } \\
\text { gas/biogas upgrade }\end{array}$ & [40] \\
\hline & \multirow{2}{*}{$\begin{array}{l}\text { Agave } \\
\text { sisalana }\end{array}$} & $\begin{array}{l}\text { Hand- } \\
\text { grinding }\end{array}$ & - & - & 800 & $\sim 600-1900$ & $0.3-1.0$ & $\mathrm{Mi}$ & \multirow[t]{2}{*}{$20-50$} & \multirow[t]{2}{*}{ Pharmaceuticals removal } & \multirow[t]{2}{*}{ [41] } \\
\hline & & Solution & - & - & 800 & $\sim 1400$ & $0.7-0.9$ & $\mathrm{Mi}+\mathrm{Me}$ & & & \\
\hline & $\begin{array}{l}\text { Lignocellulosic } \\
\text { residues }\end{array}$ & $\begin{array}{l}\text { Hand- } \\
\text { grinding }\end{array}$ & & $\begin{array}{c}\mathrm{N}-1.3- \\
1.5\end{array}$ & 900 & $\sim 1500-1700$ & $0.6-0.7$ & $\mathrm{Mi}$ & n.d. & Biogas purification & [42] \\
\hline & $\begin{array}{c}\text { Chitosan+ } \\
\text { glutaraldehyde }\end{array}$ & Solution & - & $\begin{array}{l}\mathrm{N}- \\
\sim 4.12\end{array}$ & 800 & 1013 & 0.58 & $\mathrm{Mi}+\mathrm{Me}+\mathrm{Ma}$ & n.d. & Supercap & [44] \\
\hline & $\begin{array}{c}\text { Glucose, } \\
\text { soybean meal }\end{array}$ & \multirow{2}{*}{$\begin{array}{l}\text { Solution+ } \\
\text { freeze } \\
\text { drying }\end{array}$} & \multirow[t]{2}{*}{$\mathrm{KCl}$} & $\begin{array}{c}\mathrm{N}-0.4- \\
0.5\end{array}$ & $\begin{array}{l}800- \\
850\end{array}$ & $2000-2600$ & $0.8-1.2$ & $\mathrm{Mi}+\mathrm{Me}+\mathrm{Ma}$ & $14-16$ & \multirow[t]{2}{*}{ Supercap } & [45] \\
\hline & Tannic acid & & & - & $\begin{array}{l}750- \\
900\end{array}$ & 2300-2700 & $\sim 1-1.4$ & $\mathrm{Mi}+\mathrm{Me}+\mathrm{Ma}$ & $32-38$ & & [48] \\
\hline & & & & & & & & & & & \\
\hline & Lignin & Ball milling & Urea & $\mathrm{N}-\sim 6-9$ & 800 & $\begin{array}{l}\text { ca. } 2000- \\
3000\end{array}$ & $\sim 1.2-2.1$ & $\mathrm{Mi}+\mathrm{Me}$ & 13 & Supercap & [52] \\
\hline & Biomass & Ball milling & Melamine and/or urea & $\begin{array}{c}\mathrm{N}-\sim 4- \\
12\end{array}$ & 800 & $1200-3200$ & $0.7-2.1$ & $\mathrm{Mi}+\mathrm{Me}$ & & Li-S batteries & [53] \\
\hline & Biochar & $\begin{array}{l}\text { Hand- } \\
\text { grinding }\end{array}$ & Urea & $\mathrm{N}-1.2$ & 850 & $\sim 1000-1600$ & $0.5-0.8$ & $\mathrm{Mi}$ & n.d. & Supercap & [43] \\
\hline \multirow{10}{*}{$\begin{array}{l}\text { Potassium } \\
\text { bicarbonate }\end{array}$} & Biomass & $\begin{array}{l}\text { Hand- } \\
\text { grinding }\end{array}$ & - & - & $\begin{array}{l}600- \\
900\end{array}$ & $600-1900$ & $0.3-1.4$ & $\mathrm{Mi}+\mathrm{Me}+\mathrm{Ma}$ & $4-16$ & Supercap & [56] \\
\hline & Hydrochar & Solution & Urea & $\mathrm{N}-42$ & 850 & $2000-2300$ & $0.9-1.4$ & $\mathrm{Mi}+\mathrm{Me}$ & $1.4-4$ & Supercap & [37] \\
\hline & Biochar & $\begin{array}{l}\text { Hand- } \\
\text { grinding }\end{array}$ & Urea & $\mathrm{N}-0.6$ & 850 & $\sim 800-1500$ & $0.4-0.6$ & $\mathrm{Mi}$ & n.d. & Supercap & [43] \\
\hline & Histidine & Solution & _- & $\begin{array}{c}\mathrm{N}-\mathrm{ca} \\
4-15\end{array}$ & $\begin{array}{l}700- \\
900\end{array}$ & $700-1600$ & $0.9-2.0$ & $\mathrm{Mi}+\mathrm{Me}+\mathrm{Ma}$ & n.d. & $\begin{array}{l}\text { Supercap and carbon } \\
\text { capture }\end{array}$ & {$[57]$} \\
\hline & Chestnut shell & Solution & - & - & 850 & $\sim 1850-2300$ & $1.0-1.5$ & $\mathrm{Mi}+\mathrm{Me}+\mathrm{Ma}$ & n.d. & Supercap & $7^{-158]^{-1}}$ \\
\hline & Eggplant & $\begin{array}{c}\text { Solution+ } \\
\text { freeze } \\
\text { drying }\end{array}$ & - & $N-2.7$ & $\begin{array}{l}600- \\
900\end{array}$ & $111-1226$ & $0.07-0.7$ & $\mathrm{Mi}+\mathrm{Me}+\mathrm{Ma}$ & n.d. & $\begin{array}{l}\text { Capacitive desalination } \\
\text { and ORR/OER }\end{array}$ & [59] \\
\hline & Corn stalks & $\begin{array}{l}\text { Hand- } \\
\text { grinding }\end{array}$ & Ferric chloride & - & 800 & 1313 & 0.80 & $\mathrm{Mi}+\mathrm{Me}+\mathrm{Ma}$ & n.d. & Extraction of carbamates & [60] \\
\hline & $\begin{array}{l}\text { Eucalyptus } \\
\text { leaves }\end{array}$ & $\begin{array}{l}\text { Hand- } \\
\text { grinding }\end{array}$ & - & $N-1.7$ & $\begin{array}{l}750- \\
950\end{array}$ & $1183-2133$ & $\sim 0.8-1.3$ & $\mathrm{Mi}+\mathrm{Me}$ & n.d. & $\begin{array}{c}\text { Supercap and Li-ion } \\
\text { battery }\end{array}$ & [61] \\
\hline & Chitin & Solution & - & $\mathrm{N}-2.5$ & 800 & n.d. & n.d. & n.d. & n.d. & Li- $\mathrm{O}_{2}$ battery & 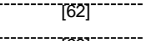 \\
\hline & Cattail fibers & Hand- & Melamine & $\mathrm{N}-6.4$ & 900 & 2345 & 1.42 & $\mathrm{Mi}+\mathrm{Me}$ & n.d & ORR & 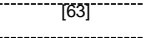 \\
\hline
\end{tabular}




\begin{tabular}{|c|c|c|c|c|c|c|c|c|c|c|c|}
\hline & & grinding & & & & & & & & & \\
\hline & $\begin{array}{l}\text { Shiitake } \\
\text { mushroom }\end{array}$ & $\begin{array}{l}\text { Hand- } \\
\text { grinding }\end{array}$ & - & $N-1.3$ & 900 & 1790 & 1.12 & $\mathrm{Mi}+\mathrm{Me}$ & 15.1 & $\begin{array}{l}\text { Supercap and Na-ion } \\
\text { battery }\end{array}$ & [64] \\
\hline & Pomelo peel & Solution & $\mathrm{NH}_{4} \mathrm{H}_{2} \mathrm{PO}_{4}$ & $\begin{array}{l}N-0.7 \\
P-0.12\end{array}$ & 800 & 2726 & 1.73 & $\mathrm{Mi}+\mathrm{Me}$ & n.d & Capacitive deionization & [65] \\
\hline & $\begin{array}{l}\text { Sophora } \\
\text { flowers }\end{array}$ & $\begin{array}{l}\text { Hand- } \\
\text { grinding }\end{array}$ & $\mathrm{MgO}$ & $N-n . s$. & 800 & $1800-2500$ & n.d. & $\mathrm{Mi}+\mathrm{Me}$ & n.d. & Water remediation & [66] \\
\hline & Biochar & Ball milling & - & $\begin{array}{c}\mathrm{N}-0.8- \\
4.5\end{array}$ & 800 & $\sim 1600-2100$ & $1.0-1.1$ & $\mathrm{Mi}$ & $15-17^{[f]}$ & Supercap and ORR & [67] \\
\hline & Biochar & Ball milling & Melamine & $N-11.6$ & 800 & 1676 & 1.03 & $\mathrm{Mi}+\mathrm{Me}$ & n.d. & ORR & {$[68]$} \\
\hline & Biochar & Solutiob & - & - & $\begin{array}{l}600- \\
800\end{array}$ & $1430-2360$ & $0.6-1.3$ & $\mathrm{Mi}+\mathrm{Me}$ & n.d. & Capacitive deionization & [69] \\
\hline & Hydrochar & $\begin{array}{l}\text { Hand- } \\
\text { grinding }\end{array}$ & - & - & 850 & $\sim 1100-1300$ & $0.55-0.72$ & $\mathrm{Mi}+\mathrm{Me}$ & n.d. & Water remediation & [70] \\
\hline & Hydrochar & $\begin{array}{l}\text { Hand- } \\
\text { grinding }\end{array}$ & - & - & 850 & 1057 & 0.64 & $\mathrm{Mi}+\mathrm{Me}+\mathrm{Ma}$ & n.d. & Supercap & [71] \\
\hline & Hydrochar & $\begin{array}{l}\text { Hand- } \\
\text { grinding }\end{array}$ & - & $\begin{array}{c}\mathrm{N}-0.6- \\
1.1\end{array}$ & 800 & $2200-2400$ & $0.9-1.1$ & $\mathrm{Mi}+\mathrm{Me}$ & n.d. & $\begin{array}{c}\text { Supercap and carbon } \\
\text { capture }\end{array}$ & [72] \\
\hline \multirow{3}{*}{$\begin{array}{l}\text { Sodium } \\
\text { carbonate }\end{array}$} & Chitosan & Solution & - & $\begin{array}{l}\mathrm{N}-2.4- \\
6.5\end{array}$ & $\begin{array}{l}600- \\
900\end{array}$ & $440-1150$ & $0.2-0.7$ & $\mathrm{Mi}$ & n.d. & - & [73] \\
\hline & Chitosan & Solution & - & $N-3-8$ & $\begin{array}{l}500- \\
700\end{array}$ & $\sim 10-1330$ & $0.04-0.78$ & $\mathrm{Mi}+\mathrm{Me}$ & n.d. & Carbon capture & [74] \\
\hline & Cork & $\begin{array}{l}\text { Hand- } \\
\text { grinding }\end{array}$ & - & $N-1.9$ & 700 & 386 & 0.16 & $\mathrm{Mi}$ & 21 & - & [75] \\
\hline \multirow{6}{*}{$\begin{array}{l}\text { Sodium } \\
\text { bicarbonate }\end{array}$} & $\begin{array}{c}\text { Shiitake } \\
\text { mushroom }\end{array}$ & $\begin{array}{l}\text { Hand- } \\
\text { grinding }\end{array}$ & - & - & 900 & 1110 & 0.83 & $\mathrm{Mi}+\mathrm{Me}$ & 15.0 & $\begin{array}{c}\text { Supercap and } \mathrm{Na} \text {-ion } \\
\text { battery }\end{array}$ & [64] \\
\hline & Glucose & Solution & Thiourea & $\begin{array}{c}N-3.4- \\
9.6 \\
S-0.2- \\
0.4\end{array}$ & 700 & $1044-1608$ & $0.7-1.0$ & $\mathrm{Mi}+\mathrm{Me}+\mathrm{Ma}$ & n.d. & Pharmaceuticals removal & [76] \\
\hline & Flour & Solution & - & $\mathrm{N}-0.41$ & 1000 & 1376 & 0.99 & $\mathrm{Mi}+\mathrm{Me}+\mathrm{Ma}$ & n.d. & Supercap & {$[77]^{-7}$} \\
\hline & Microalgae & $\begin{array}{l}\text { Hand- } \\
\text { grinding }\end{array}$ & - & $N-2-10$ & $\begin{array}{l}600- \\
800\end{array}$ & $\sim 280-1500$ & $\sim 0.2-0.9$ & $\mathrm{Mi}+\mathrm{Me}+\mathrm{Ma}$ & n.d. & Supercap & [78] \\
\hline & & & $\begin{array}{c}\mathrm{Na}_{2} \mathrm{CO}_{3} / \\
\mathrm{K}_{2} \mathrm{CO}_{3}\end{array}$ & $N-1.07$ & 700 & 1278 & 0.68 & \multirow{2}{*}{$\mathrm{Mi}+\mathrm{Me}+\mathrm{Ma}$} & \multirow{2}{*}{ n.d. } & \multirow{2}{*}{$\begin{array}{c}\text { Carbon capture and water } \\
\text { remediation }\end{array}$} & \multirow[t]{2}{*}{109} \\
\hline & Wheat flour & Solution & $\begin{array}{c}\mathrm{Na}_{2} \mathrm{CO}_{3} / \\
\mathrm{K}_{2} \mathrm{CO}_{3} / \text { dicyandiamide }\end{array}$ & $\begin{array}{c}N-7.3- \\
12.2\end{array}$ & $\begin{array}{l}600- \\
900 \\
\end{array}$ & $\sim 650-3040$ & $0.4-1.9$ & & & & \\
\hline \multirow{4}{*}{$\begin{array}{l}\text { Potassium } \\
\text { oxalate }\end{array}$} & Phenolic resin & $\begin{array}{c}\text { During } \\
\text { synthesis }\end{array}$ & - & - & 800 & $760-2130$ & $\sim 0.3-0.8$ & $\mathrm{Mi}$ & n.d. & Carbon capture & [84] \\
\hline & $\begin{array}{l}\text { Semen } \\
\text { cassiae }\end{array}$ & Solution & - & $\begin{array}{c}\mathrm{N}-0.5- \\
0.9\end{array}$ & $\begin{array}{l}600- \\
800\end{array}$ & $655-1100$ & $\sim 0.5-0.6$ & $\mathrm{Mi}+$ meso & $60-70$ & Supercap & [85] \\
\hline & Glucose & $\begin{array}{l}\text { Hand- } \\
\text { grinding }\end{array}$ & - & - & 850 & 2575 & $\sim 1.5$ & $\mathrm{Mi}+\mathrm{me}$ & n.d. & $\begin{array}{l}\text { Catalyst }(\mathrm{Rh}) \text { for } \mathrm{H}_{2} \\
\text { production }\end{array}$ & [87] \\
\hline & Hydrochar & Hand- & - & - & 800 & $\sim 1700-2500$ & $\sim 0.9-1.5$ & $\mathrm{Mi}+\mathrm{me}$ & n.d. & & "7885" \\
\hline
\end{tabular}




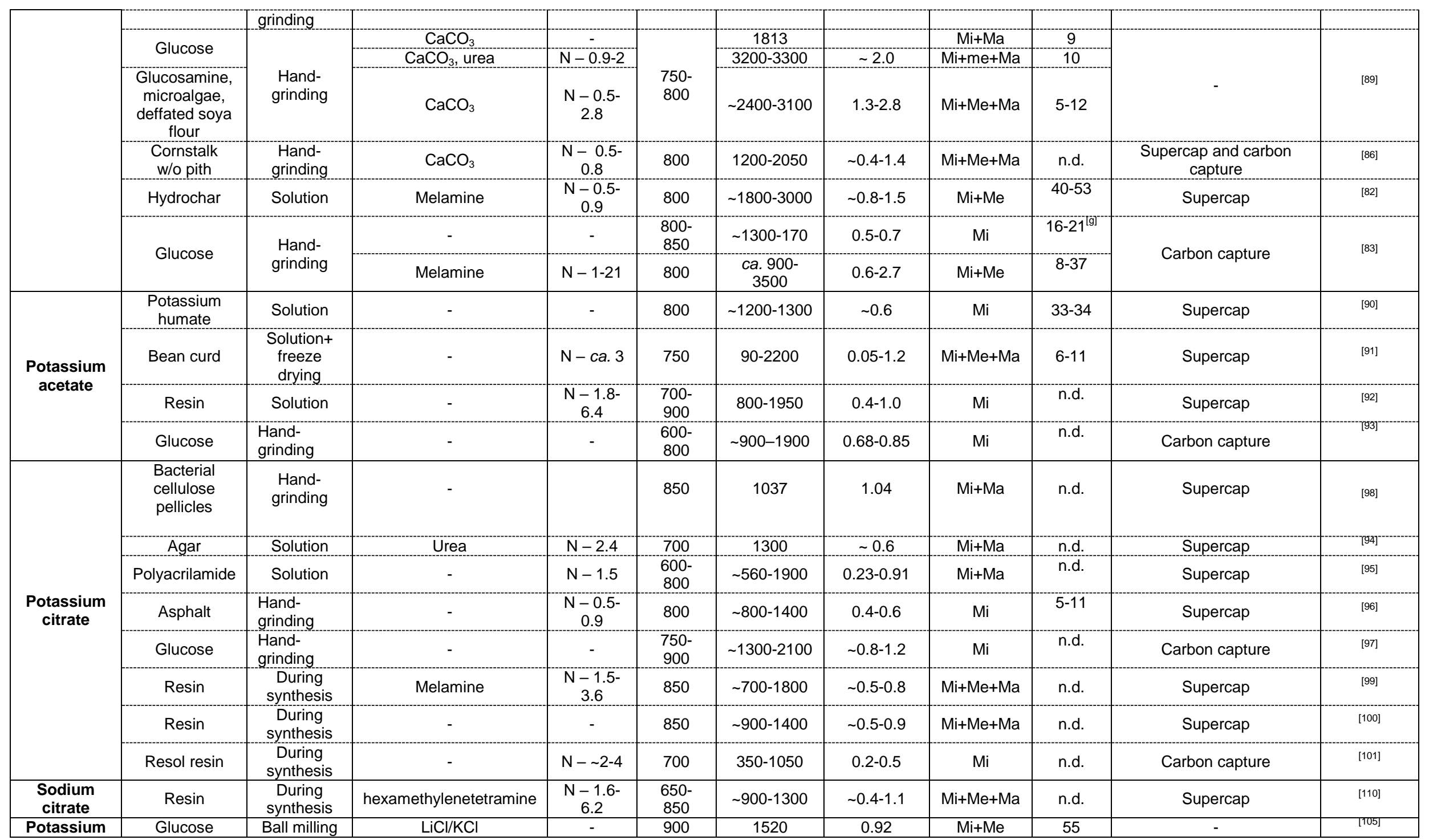




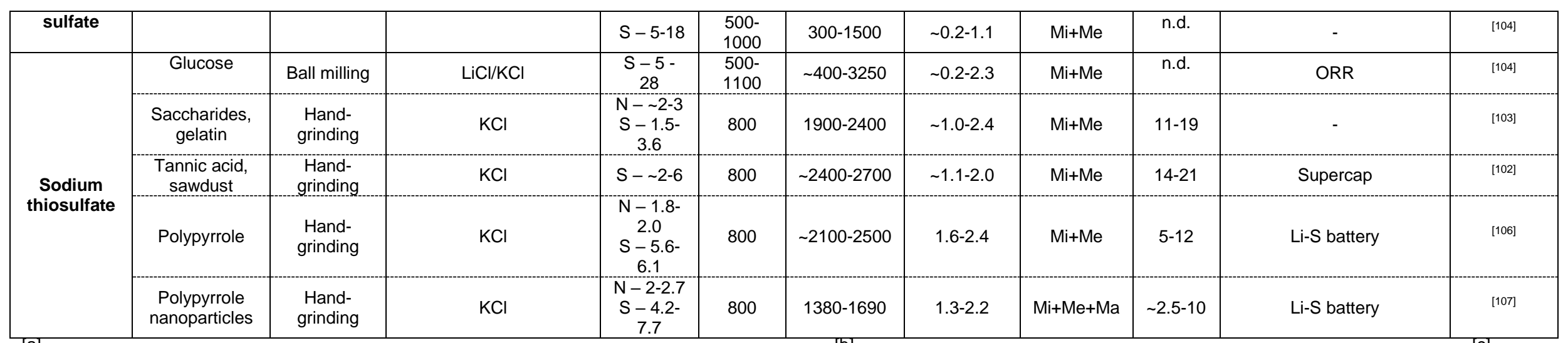

${ }^{[a]}$ Depending on the work, the values are provided in at \% or wt \%. ${ }^{[b]}$ Total pore volume determined by $\mathrm{N}_{2}$ physisorption. ${ }^{[c]}$ Mi microporous, $\mathrm{Me}$ - mesoporous and $\mathrm{Ma}$ - macroporous pore network. ${ }^{[\mathrm{d}]}$ Carbon yield is defined as $\mathrm{g}$ of porous carbon/100 $\mathrm{g}$ of raw carbon precursor. ${ }^{[\mathrm{e}]} \mathrm{A}$ yield of $30 \%$ is assumed for the hydrothermal carbonization step. ${ }^{[\mathrm{f}]} \mathrm{A}$ yield of $40 \%$ is assumed for the carbonization step at $400 \stackrel{\circ}{\circ} .^{[g]}$ A yield of $40 \%$ is assumed for the hydrothermal carbonization step. 


\section{Self-Activation Methods}

The self-activation technique involves the production of porous carbons without the use of any foreign activating compounds, the porogenic action being exclusively performed by substances that are part of the carbon precursor. In this way, carbon materials with notable pore development are produced, comparable to that produced by means of conventional activating techniques. This methodology has two important and obvious advantages: a) it avoids the use of activating agents that are in many cases harmful and corrosive, and b) it is easy and cheap given that the carbon precursors are low-cost, readilyavailable products. Raw materials appropriate to be carbon precursors need to include one of the following elements in their composition: alkali metals $(\mathrm{K}, \mathrm{Na})$, alkali earth metals $(\mathrm{Ca}, \mathrm{Mg})$ or other elements such as $\mathrm{Fe}$ or $\mathrm{Zn}$. A variety of simple organic salts (i.e. citrates, acetates, gluconates, tartrates, alginates, etc.) or polymeric salts (i.e. polystyrene-based, etc.) meet this requirement. Importantly, this technique can also be applied to certain biomass materials which contain appreciable amounts of alkali elements (i.e. $\mathrm{K}, \mathrm{Na}$ ).

\subsection{Self-Activation Mechanisms}

The self-activation of the organic or polymeric salts involves three pore generation mechanisms: i) chemical activation (oxidation of carbon by carbonates or oxides), ii) physical activation (gasification of carbon by the $\mathrm{CO}_{2}$ produced in situ), and iii) removal of inorganic nanoparticles embedded in the carbon matrix (endo-template processes). Figure 8 schematically illustrates the self-activation process. 


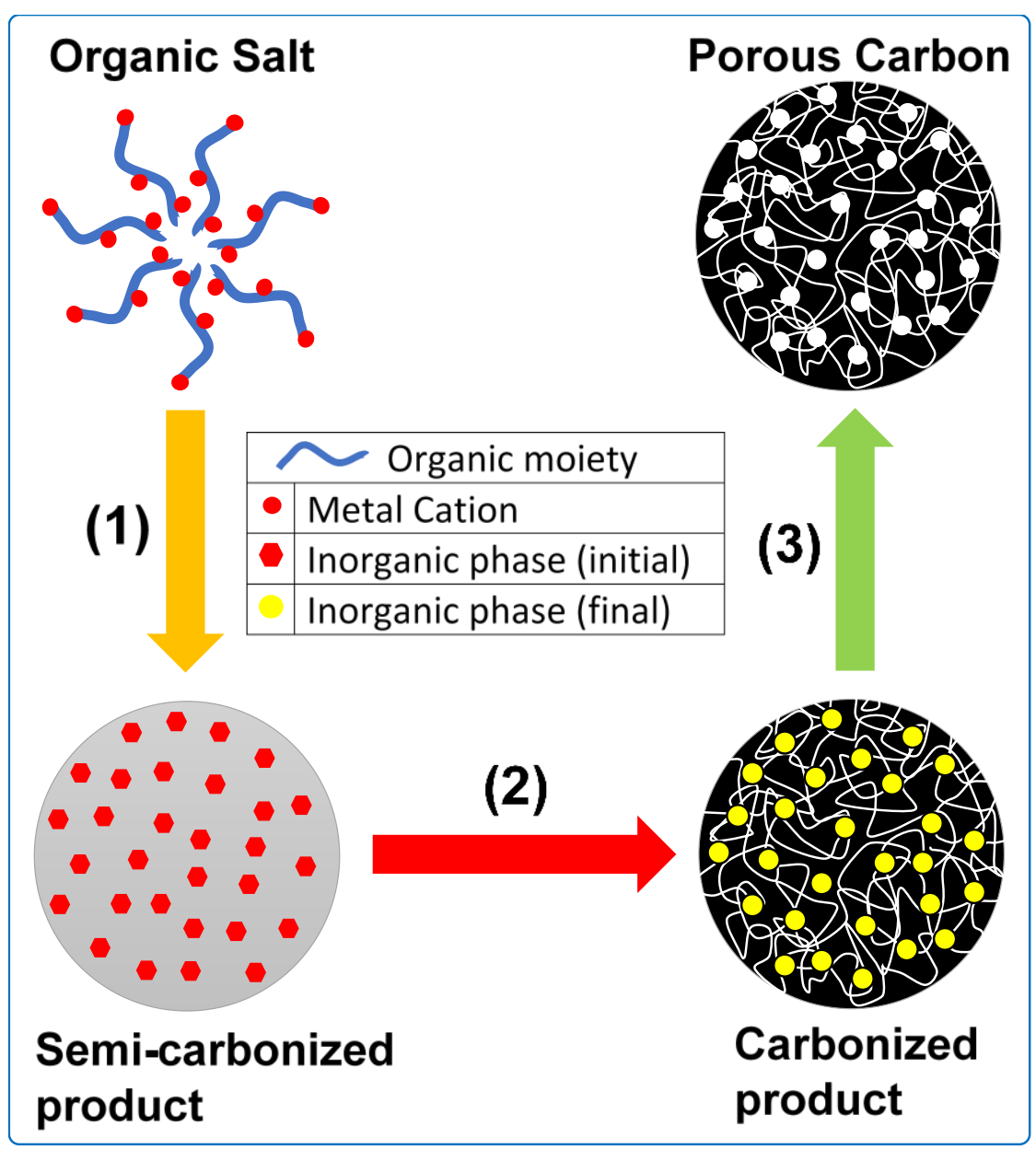

Figure 8. Schematic illustration of the self-activation process of an organic salt: (1) partial decomposition of the organic salt that includes the salt melting and the formation of the initial inorganic phase $\left(T<400^{\circ} \mathrm{C}\right)$, (2) carbonization and activation $\left(\mathrm{T}>400^{\circ} \mathrm{C}\right.$ ), and (3) removal of the inorganic products.

During the first steps of the thermal treatment $\left(<300^{\circ} \mathrm{C}\right)$ of an organic salt, three important processes occur: i) melting of the raw salt (most of the organic salts melt at temperatures below $300^{\circ} \mathrm{C}$ ), ii) dehydration and decarboxylation reactions ${ }^{[111,112]}$ and iii) formation of the inorganic species (i.e. carbonates, sulfates or oxides). At this point, the melted semi-carbonized mass is covering the inorganic nanoparticles, which ensures very close contact between the carbonaceous matter and the inorganic particles that act as activation agents. Furthermore, the melting phenomenon has another significant effect since the final morphology of the carbon particles is pre-shaped in this stage. In some cases, the pyrolysis of organic salts leads to free or interconnected porous carbon nanosheets that have a thickness $<100 \mathrm{~nm} .^{[113-118]}$ This is an important achievement since this kind of morphology provides short diffusional paths, which is extremely important for many applications that require fast adsorption-desorption rates (e.g. supercapacitors, sodium-ion batteries, hybrid-ion capacitors, etc.). ${ }^{[119]}$

The potassium organic salts are especially interesting since they normally lead to carbon materials with a high pore development. During 
decomposition of potassium organic salts, $\mathrm{K}_{2} \mathrm{CO}_{3}$ appears at around $300^{\circ} \mathrm{C} .^{[120]}$ At higher temperatures $\left(>600-700^{\circ} \mathrm{C}\right.$ ), $\mathrm{K}_{2} \mathrm{CO}_{3}$ oxidizes the carbon according to reactions (1) to (4) described in Section 2, leading to the formation of an extensive pore network made up mainly of micropores and small mesopores, as previously discussed.

The above description is appropriate for potassium salts, but it is not entirely applicable to sodium salts. As noted in Section 2.1, $\mathrm{Na}_{2} \mathrm{CO}_{3}$ is less effective than $\mathrm{K}_{2} \mathrm{CO}_{3}$ and its role as an activating agent is limited to reaction (10) since it decomposes above $1000^{\circ} \mathrm{C}$, i.e. beyond the typical carbonization temperatures, so that most of the sodium carbonate remains unaltered. Then, the unreacted $\mathrm{Na}_{2} \mathrm{CO}_{3}$ nanoparticles operate as an endo-template leading in many cases to the formation of macroporous carbon sponges once they are removed. ${ }^{[115,121]}$

In the case of the thermal decomposition of alkali earth metal organic salts (i.e. $\mathrm{Ca}, \mathrm{Mg}$ ), the corresponding carbonates cannot oxidize the carbonaceous matter and they simply decompose, generating oxide nanoparticles and $\mathrm{CO}_{2}\left[\mathrm{MCO}_{3} \rightarrow \mathrm{MO}+\mathrm{CO}_{2}\right]$. In the case of calcium carbonate, since the decomposition occurs at high temperatures $\left(>750^{\circ} \mathrm{C}\right)$, it can be assumed that the emitted $\mathrm{CO}_{2}$ will react with carbon according to Equation (3) generating a certain number of micropores. However, in the case of $\mathrm{MgCO}_{3}$, the decomposition occurs at $\mathrm{T}<600{ }^{\circ} \mathrm{C}^{122]}$ and, accordingly, the reaction between the released $\mathrm{CO}_{2}$ and the carbonaceous matter is irrelevant. Furthermore, considering the fact that the oxide nanoparticles generated by the decomposition of the carbonates (i.e., $\mathrm{CaO}$ or $\mathrm{MgO}$ with sizes below $50 \mathrm{~nm}$ ) are embedded within the carbon matrix, they play an important role because they will act as endo-templates leading to large mesopores once the carbonized sample is washed with an acid. In the case of the pyrolysis of organic salts of $\mathrm{Fe}$ or $\mathrm{Zn}$, the formation of the corresponding oxides $\left(\mathrm{Fe}_{2} \mathrm{O}_{3}\right.$ or $\left.\mathrm{ZnO}\right)$ takes place firstly at $\mathrm{T}<400^{\circ} \mathrm{C} .^{[123]}$ At higher temperatures $\left(>600^{\circ} \mathrm{C}\right.$ in the case of $\mathrm{Fe}_{2} \mathrm{O}_{3}$ or $>850^{\circ} \mathrm{C}$ in the case of $\mathrm{ZnO}$ ), these oxides are reduced by the carbonaceous matter to the corresponding metals [MO $+\mathrm{C} \rightarrow \mathrm{M}+\mathrm{CO}$ ]. This reaction causes the creation of a certain number of pores, and the subsequent acid etching of the embedded metal nanoparticles will create an additional mesoporous network. In the case of organic zinc salts, it is important to note that, because zinc vaporizes at $\sim 910^{\circ} \mathrm{C}$, carbonization above $950{ }^{\circ} \mathrm{C}$ produces an inorganicfree porous carbon and no additional acid leaching is needed. ${ }^{[24]}$

Table 2 summarizes the main characteristics and applications of the porous carbons produced by self-activation of organic salts. This table includes the type of organic salt, the additives employed and degree of heteroatom doping, the textural properties, the type of morphology, and the carbon yield.

\subsection{Porous carbons from alkali metal organic salts}

Since it has been proven that the carbonization of organic salts leads to carbons with high pore development, a wide variety of these types of substances have been investigated as precursors of porous carbons. To this end, special attention has been paid to organic salts of potassium and sodium because of the well-proven capacity of the alkali compounds as activating agents. 
In 2004, Hines et al. demonstrated for the first time that a porous carbon could be obtained without the use of an external activating agent. ${ }^{[125]}$ They reported that the carbonization of the sodium salt of poly(styrene sulfonic acidco-maleic acid) yields a microporous carbon with a sponge-like structure exhibiting a high BET surface area of $1380 \mathrm{~m}^{2} \mathrm{~g}^{-1}$. Subsequently, our group showed that a variety of porous carbons could be easily synthesized by means of the pyrolysis of simple organic salts that combine an organic moiety with appropriate cations ( $\mathrm{K}, \mathrm{Na}, \mathrm{Ca}, \mathrm{Fe}$ or $\mathrm{Zn}){ }^{[35]}$ In this respect, we discovered that the pyrolysis of potassium citrate or sodium gluconate leads to carbon nanosheets. In particular, porous carbon particles with a (rose-dessert)-like morphology built up of interconnected carbon nanosheets (Figure 9a) were prepared by the pyrolysis of potassium citrate..$^{[35,113]}$ These nanosheets have a thickness of around $50 \mathrm{~nm}$, a high surface area up to $2220 \mathrm{~m}^{2} \mathrm{~g}^{-1}$, porosity made up of narrow micropores and small mesopores, and good electrical conductivity (Figures 9b-d). In the case of sodium gluconate, the pyrolysis of this salt leads to a porous carbon that has a unique morphology consisting of individual carbon nanosheets with a very large aspect ratio (length $>100 \mu \mathrm{m}$ and thickness $<200 \mathrm{~nm}$ ), as illustrated in Figure 9e. ${ }^{[116]}$ These carbon nanosheets exhibit a BET surface area up to $1390 \mathrm{~m}^{2} \mathrm{~g}^{-1}$ and a hierarchical porosity made up of large cage-like spherical mesopores $(\sim 10-20 \mathrm{~nm})$ interconnected by narrow micropores (Figures 9f-i). Yang et al. studied the pyrolysis of sodium citrate and found that, whereas at low temperatures (400$500^{\circ} \mathrm{C}$ ) the formation of carbon dots takes place, higher temperatures (> $600^{\circ} \mathrm{C}$ ) produce a sponge-like structure built up of thin carbon sheets that have an area of around $200 \mathrm{~m}^{2} \mathrm{~g}^{-1} .{ }^{[115]}$ The self-activation occurs not only with simple organic salts, but certain polymeric salts are also able to produce porous carbons. ${ }^{[125-128]}$ In a typical example, Roberts et al. reported the self-activation of sodium poly(4-styrenesulfonate). ${ }^{[128]}$ During the thermal treatment of this salt, the pyrolysis of the polymeric moiety occurs and then the generated carbonaceous matter is chemically activated by the $\mathrm{Na}_{2} \mathrm{SO}_{4}$ generated in situ (Reactions 12 and 13 in Section 2.3).
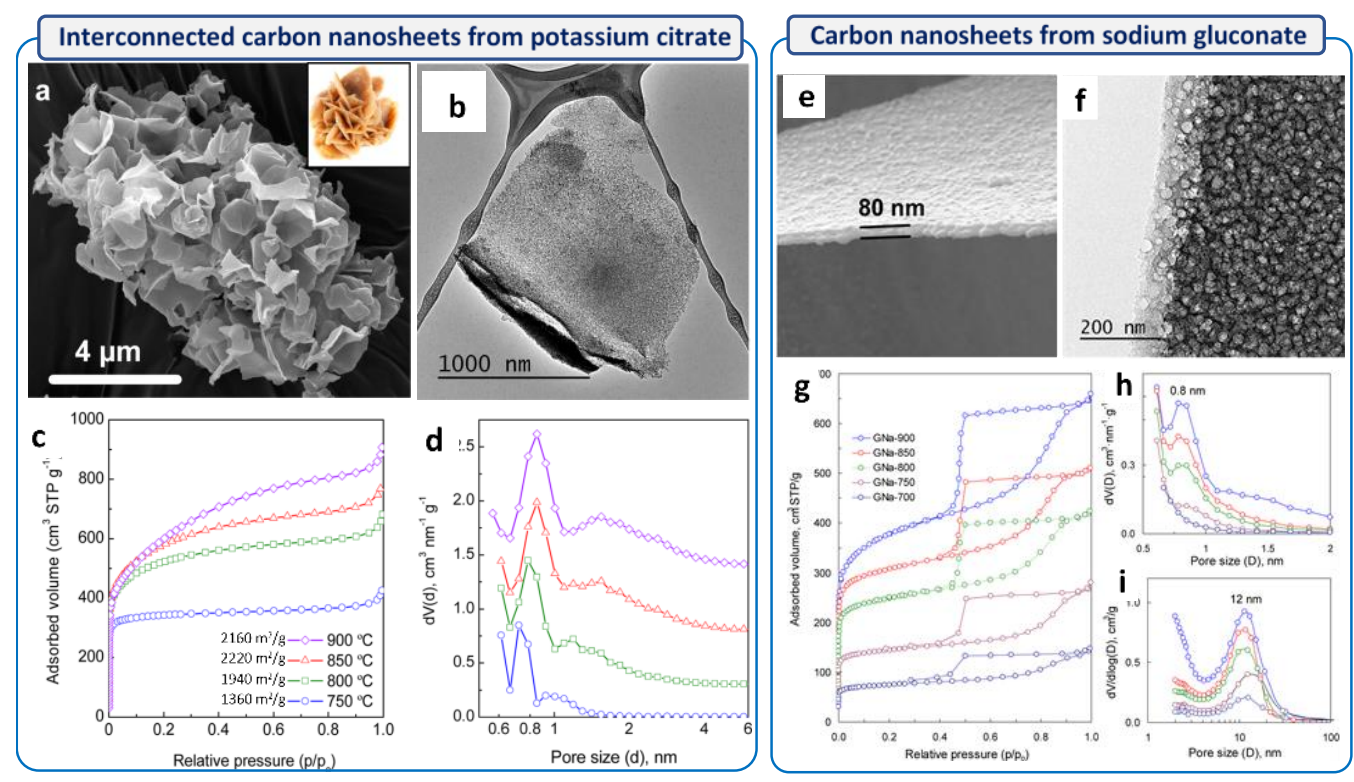
Figure 9. Interconnected porous carbon nanosheets produced by self-activation of potassium citrate: a) SEM and b) TEM images, and c) $\mathrm{N}_{2}$ adsorption isotherms and d) pore size distributions (Reproduced with permission from ref. [113]. Copyright 2014, American Chemical Society). Carbon nanosheets synthesized by self-activation of sodium gluconate: e) SEM and f) TEM images, and g) $\mathrm{N}_{2}$ adsorption isotherms and h,i) pore size distributions (Reproduced with permission from ref. [116]. Copyright 2015, American Chemical Society).

Sometimes, in order to provide the porous carbon with specific properties, certain substances (additives) have been used simultaneously. These additives are not a source of carbon, but cause the incorporation of certain types of heteroatoms in the carbon framework ${ }^{[114,129,130]}$ or promote pore development. ${ }^{[120]}$ Gao et al. pyrolyzed sodium citrate together with cysteine, producing a N, S-doped porous carbon with a sponge-like structure. ${ }^{[130]}$ In another approach, our group recently demonstrated that the addition of urea to potassium citrate leads to a porous carbon with ultra-high pore development (BET surface area of $3350 \mathrm{~m}^{2} \mathrm{~g}^{-1}$ ), which is considerably superior to that obtained using potassium citrate alone $\left(1970 \mathrm{~m}^{2} \mathrm{~g}^{-1}\right)$ (Figure 10). ${ }^{[120]}$

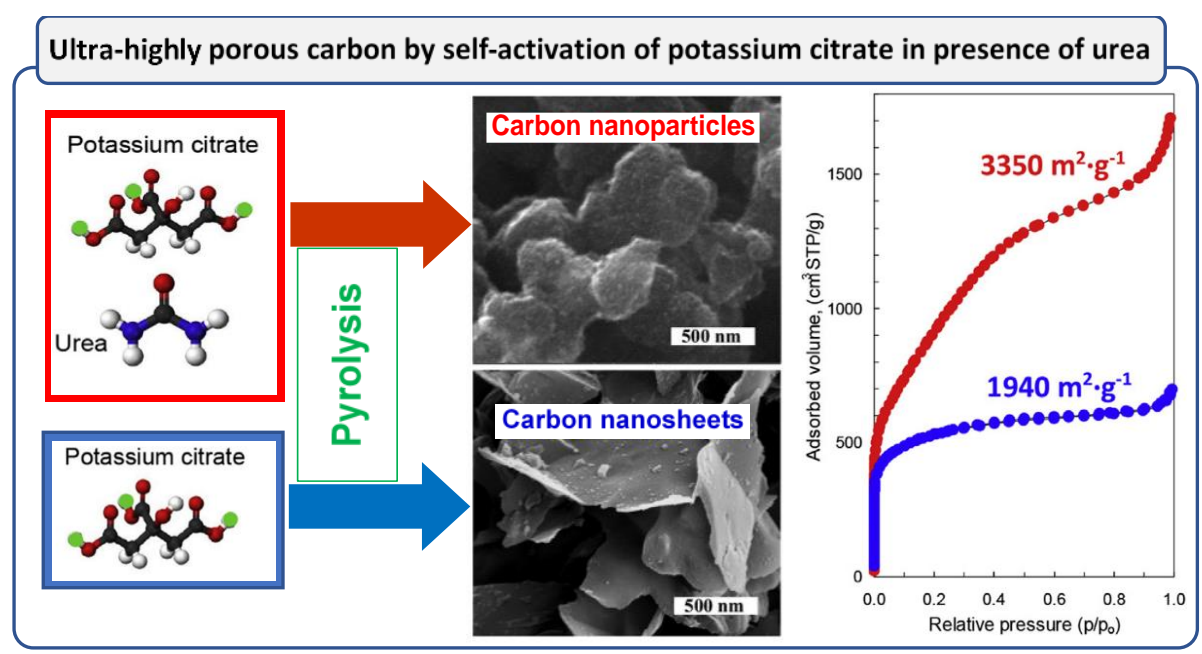

Figure 10. Schematic illustration of the synthesis of porous carbons with ultrahigh surface area by self-activation of potassium citrate in presence of urea (Reproduced with permission from ref. [120]. Copyright 2018, Elsevier Ltd).

\subsection{Porous carbons derived from organic salts of $\mathrm{Ca}, \mathrm{Mg}, \mathrm{Fe}$ and $\mathrm{Zn}$}

For the non-alkali metal organic salts, as already explained in Section 3.1, most of the porosity originates once the remaining inorganic nanoparticles (templates) are removed by acid leaching. As a clarifying example, our group observed that the pyrolysis of calcium citrate leads to a $\mathrm{CaO} / \mathrm{C}$ composite with a BET surface area of only $112 \mathrm{~m}^{2} \mathrm{~g}^{-1}$, but once the $\mathrm{CaO}$ nanoparticles are removed by acid etching, a carbon with a BET surface area of $1610 \mathrm{~m}^{2} \mathrm{~g}^{-1}$, a large pore volume of $2.6 \mathrm{~cm}^{3} \mathrm{~g}^{-1}$ and a porosity made up almost exclusively of mesopores of around $10 \mathrm{~nm}$ is obtained ${ }^{[123,131,132]}$ (Figures 11a-c). In a recent work, Wang et al. reported that the carbonization of calcium gluconate at > $800^{\circ} \mathrm{C}$ leads to a sponge-like cellular structure where the $\mathrm{CaO}$ nanoparticles 
formed are deposited on the carbon nanosheets. ${ }^{[133]}$ Tsumura et al. pyrolyzed magnesium acetate at temperatures of $900{ }^{\circ} \mathrm{C}$ obtaining a mesoporous carbon with a BET surface area of around $1800 \mathrm{~m}^{2} \mathrm{~g}^{-1}$ and a pore volume of $>2.5 \mathrm{~cm}^{3}$ $g^{-1} \cdot[134]$

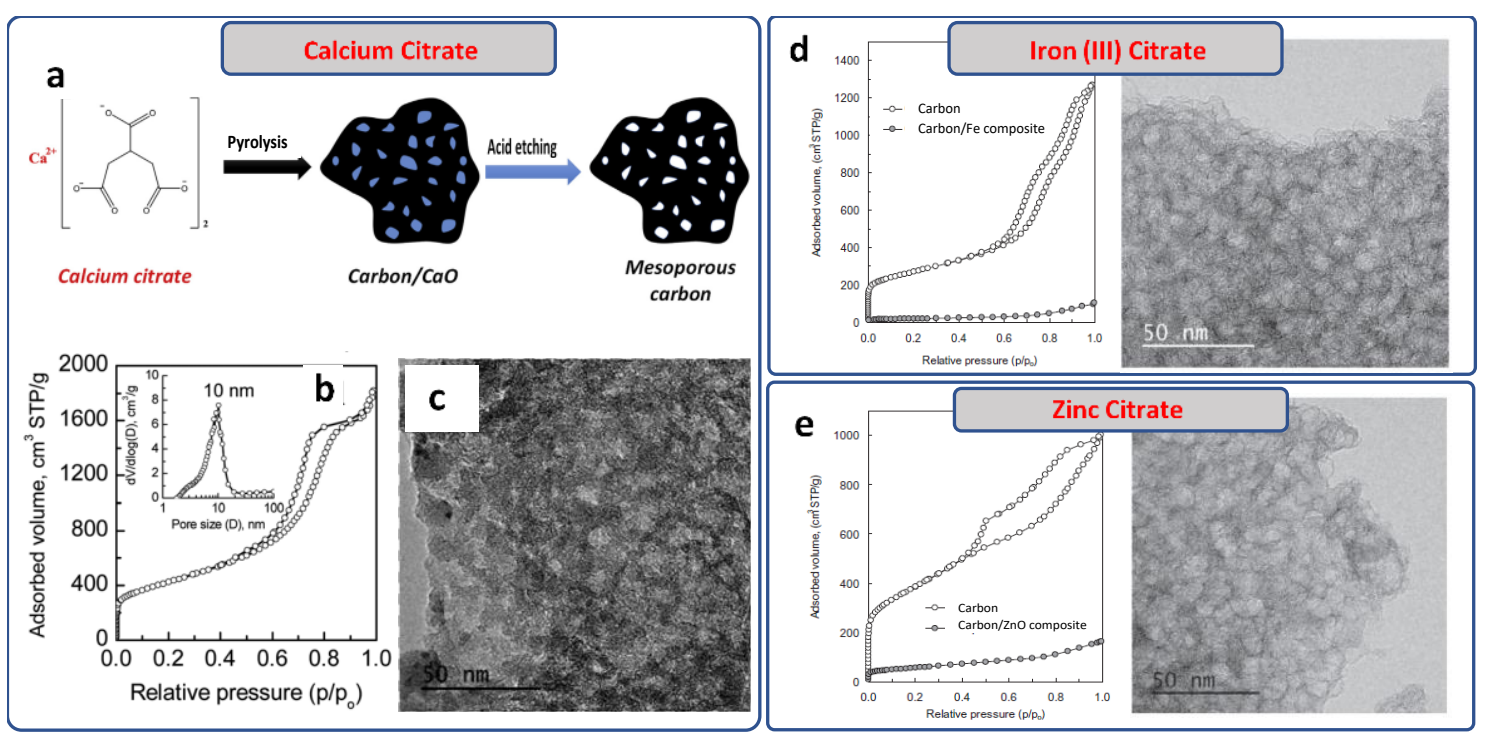

Figure 11. Mesoporous carbon produced by self-activation of calcium citrate: a) synthesis scheme (Reproduced with permission from ref. [132]. Copyright 2019, Elsevier Ltd. b) $\mathrm{N}_{2}$ sorption isotherm and PSD and c) TEM image showing the mesoporous structure (Reproduced with permission from ref. [123]. Copyright 2015, Elsevier Ltd.). Nitrogen sorption isotherm and TEM images of mesoporous carbons derived from: d) iron (III) citrate and e) zinc citrate (Reproduced with permission from ref. [123]. Copyright 2015, Elsevier Ltd.).

In the case of iron organic salts, our group showed that the carbonization of iron (III) citrate leads to a mesoporous carbon with a bimodal mesopore distribution (sizes centered around 9 and $20 \mathrm{~nm}$ ) ${ }^{[123]}$ (Figure 11d). Similarly to the iron salts, the pyrolysis of zinc organic salts also yields a mesoporous carbon, as we verified for $\mathrm{Zn}$ (II) citrate (Figure 11e). ${ }^{[123,131]}$

The well-known capacity of $\mathrm{Zn}^{2+}$ ions to attach certain organic moieties has been used to synthesize $\mathrm{Zn}$-organic coordinated compounds that are able to generate porous carbons by self-activation. Zhao et al. showed that the reaction between ethylene glycol and zinc acetate leads to zinc glycolate: (-Zn$\left.\mathrm{OCH}_{2} \mathrm{CH}_{2} \mathrm{O}-\right)_{n}$, whose pyrolysis at $600{ }^{\circ} \mathrm{C}$ and subsequent acid leaching yields porous carbon nanofibers with a high aspect ratio (length of $30 \mu \mathrm{m}$ and diameter of $240 \mathrm{~nm}$ ) and high pore development (BET surface area of $1725 \mathrm{~m}^{2}$ $\left.\mathrm{g}^{-1}\right) .{ }^{[135]}$ Recently, Tong et al. reported a general route for producing hierarchically porous carbons by means of the carbonization of (organic-Zn) compounds synthesized by coordinating $\mathrm{Zn}^{2+}$ cations with deprotonated organic ligands that possess polytopic chelating sites. ${ }^{[124]}$ They showed that combining terephthalic acid with $\mathrm{Zn}\left(\mathrm{NO}_{3}\right)_{2}$ in an aqueous alkali medium, a non-porous $\mathrm{Zn}$ organic framework is easily synthesized (Figure 12a), which, once carbonized, gives rise to a carbon that exhibits notable pore development with a hierarchical 
porosity made up of micro-mesopores with sizes at $\sim 1 \mathrm{~nm}$ and $\sim 3 \mathrm{~nm}$, a BET surface area of $2360 \mathrm{~m}^{2} \mathrm{~g}^{-1}$ and pore volume of $1.38 \mathrm{~cm}^{3} \mathrm{~g}^{-1}$ (Figures $12 \mathrm{~b}, \mathrm{c}$ ).

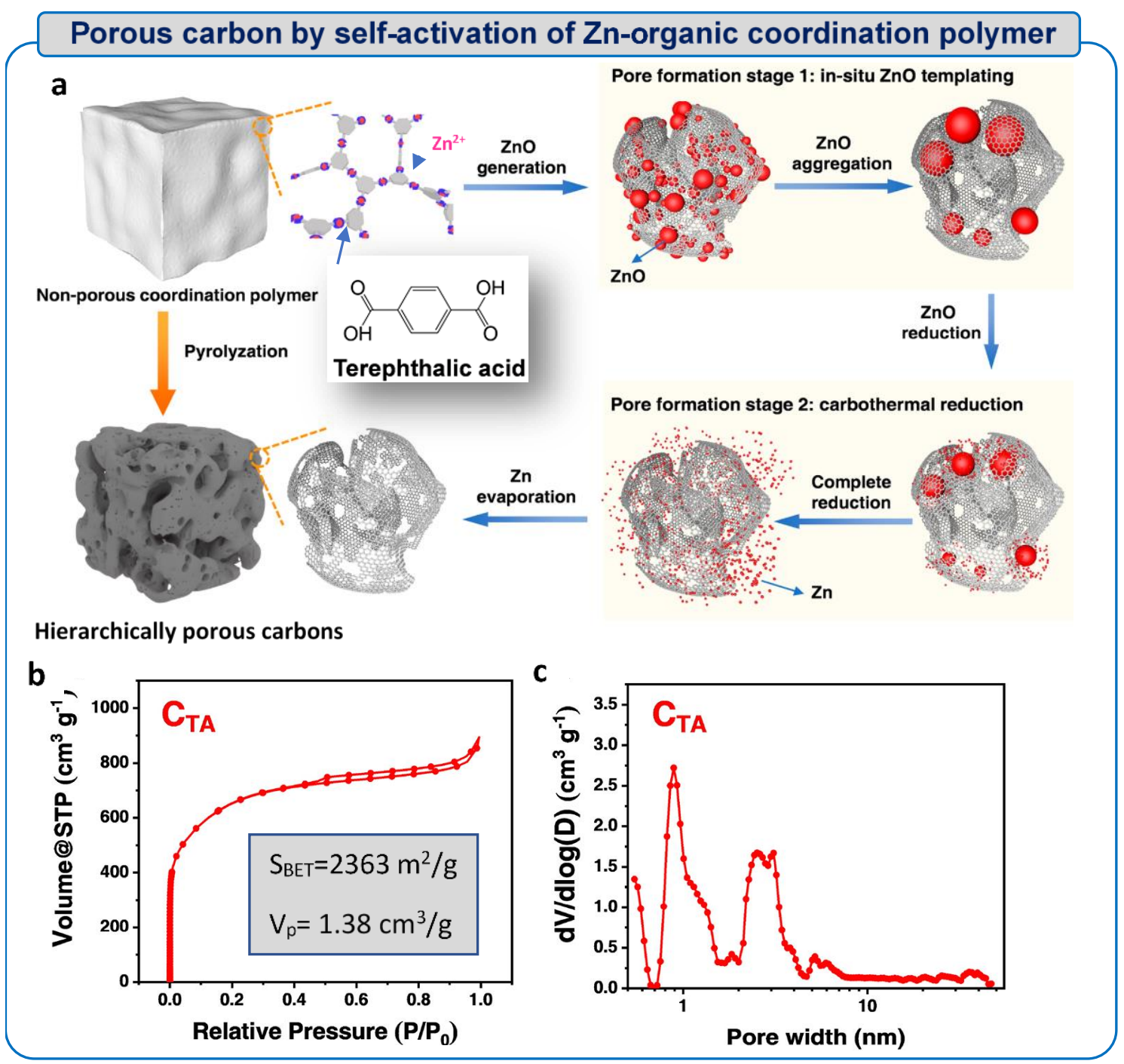

Figure 12. a) Synthesis scheme, b) $\mathrm{N}_{2}$ sorption isotherm and c) pore size distribution of hierarchically porous carbon produced by self-activation of a $\mathrm{Zn}$ terephthalic coordination polymer (Reproduced with permission from ref. [124]. Copyright 2020, American Chemical Society). 
Table 2. Summary of porous carbon prepared by self-activation of organic salts.

\begin{tabular}{|c|c|c|c|c|c|c|c|c|c|c|c|}
\hline Cation & Organic moiety & Aditives & $\begin{array}{c}\text { Doping } \\
(\%)\end{array}$ & $\begin{array}{c}\mathrm{T}_{\text {pyrolysis }} \\
\left({ }^{\circ} \mathrm{C}\right)\end{array}$ & $\begin{array}{c}\mathrm{S}_{\mathrm{BET}} \\
\left(\mathrm{m}^{2} \mathrm{~g}^{-1}\right)\end{array}$ & $\begin{array}{l}\text { Pore volume } \\
\left(\mathrm{cm}^{3} \mathrm{~g}^{-1}\right)^{[\mathrm{a}]}\end{array}$ & $\begin{array}{c}\text { Pore } \\
\text { structure }^{[\mathrm{b}}\end{array}$ & Morphology & 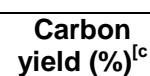 & Application & Reference \\
\hline \multirow[t]{8}{*}{$\mathrm{K}^{+}$} & \multirow[t]{3}{*}{ Citrate } & - & - & $\begin{array}{l}700-900 \\
850\end{array}$ & $\begin{array}{l}1360-2220 \\
1740\end{array}$ & $0.6-1.3$ & $\mathrm{Mi}+\mathrm{Me}$ & $\begin{array}{l}\text { Interconnected } \\
\text { nanosheets }\end{array}$ & $2-5$ & $\begin{array}{l}\text { Supercap } \\
\text { Supercap }\end{array}$ & {$[35,113,118]$} \\
\hline & & Urea & $\begin{array}{l}\mathrm{N}: 0.5- \\
4.5\end{array}$ & $700-900$ & $2750-3350$ & $1.56-2.65$ & $\mathrm{Mi}+\mathrm{Me}$ & 3D-irregular & 2.2 & Supercap & 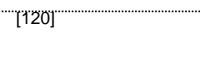 \\
\hline & & $\mathrm{NH}_{4}$ citrate & - & 800 & $940-1900$ & $0.5-0.95$ & $\mathrm{Mi}$ & $\begin{array}{l}\text { Interconnected } \\
\text { nanosheets }\end{array}$ & $24-34$ & Supercap & {$[114]$} \\
\hline & Gluconate & & & 800 & 1410 & 0.76 & $\mathrm{Mi}+\mathrm{Me}$ & 3D-irregular & 17 & - & {$[35]$} \\
\hline & Gluconate & Melamine & $\mathrm{N}: 6-17$ & $800-900$ & $730-1040$ & $0.3-0.4$ & $\mathrm{Mi}$ & 3D-irregular & $30-40$ & Supercap & 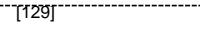 \\
\hline & Tartrate & & & $600-900$ & $400-1300$ & $0.2-0.7$ & $\mathrm{Mi}+\mathrm{Me}$ & 3D-irregular & 20 & Supercap & $-[136]$ \\
\hline & $\begin{array}{l}\text { poly(acrylamide- } \\
\text { co-acrylic acid) }\end{array}$ & & & 1000 & 1330 & - & $\mathrm{Mi}$ & sheets & - & Supercap & {$[1 T 27]^{-}$} \\
\hline & phthalate & & & $600-1000$ & $500-2100$ & $0.3-1.1$ & $\mathrm{Mi}$ & $=$ & - & $\mathrm{CO}_{2}$ capture & $-[т 57]$ \\
\hline \multirow[t]{13}{*}{$\mathrm{Na}^{+}$} & $\begin{array}{l}\text { Poly(4- } \\
\text { styrenesulfonic } \\
\text { acid-co-maleic } \\
\text { acid) }\end{array}$ & - & & $\begin{array}{l}1000 \\
800\end{array}$ & $\begin{array}{l}1720 \\
1400\end{array}$ & 0.93 & $\begin{array}{l}\mathrm{Mi}+\mathrm{Me} \\
\mathrm{Mi}+\mathrm{Me}\end{array}$ & $\begin{array}{l}\text { 3D-irregular } \\
\text { 3D-irregular }\end{array}$ & $\begin{array}{l}- \\
17\end{array}$ & Supercap & $\begin{array}{l}{[126]} \\
{[125]}\end{array}$ \\
\hline & Citrate & - & & $\begin{array}{l}400-1000 \\
750 \\
800 \\
800\end{array}$ & $\begin{array}{l}200 \\
180 \\
660 \\
650\end{array}$ & 0.40 & $\mathrm{Mi}+\mathrm{Me}$ & Sponge-like & $\begin{array}{l}3-4 \\
3-4 \\
4\end{array}$ & $\begin{array}{l}\text { Na storage } \\
\text { K-ion battery } \\
\text { Supercap }\end{array}$ & $\begin{array}{l}-[115] \\
{[121]} \\
{[117]} \\
{[35]}\end{array}$ \\
\hline & Chloroacetates & - & & $300-1000$ & $\begin{array}{l}740 \\
1020\end{array}$ & $\begin{array}{l}0.5 \\
0.4\end{array}$ & $\begin{array}{l}\mathrm{Mi}+\mathrm{Ma} \\
\mathrm{Mi}+\mathrm{Ma}\end{array}$ & $\begin{array}{l}\text { 3D-irregular } \\
\text { 3D-irregular }\end{array}$ & $\begin{array}{l}4 \\
30\end{array}$ & Supercap & $\begin{array}{l}-[138]^{-} \\
{[139]}\end{array}$ \\
\hline & Ascorbate & - & & $400-1000$ & $500-1300$ & $0.44-1.15$ & $\mathrm{Mi}+\mathrm{Me}$ & Lamellar flakes & - & Na-ion battery & - craves" \\
\hline & $\begin{array}{l}\text { EDTA disodium } \\
\text { magnesium }\end{array}$ & - & & $500-900$ & $100-1260$ & $0.1-1.2$ & $\mathrm{Mi}+\mathrm{Me}$ & 3D-irregular & $3-7$ & Supercap & -[ז4T] \\
\hline & $\begin{array}{l}\text { EDTA } \\
\text { tetrasodium }\end{array}$ & - & & $600-900$ & $410-1170$ & $0.21-0.71$ & $\mathrm{Mi}+\mathrm{Me}$ & 3D-irregular & - & Supercap & 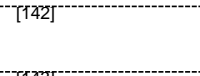 \\
\hline & $\begin{array}{l}\text { EDTA disodium } \\
\text { zinc }\end{array}$ & & & $600-900$ & $590-1470$ & $0.56-1.32$ & $\mathrm{Mi}+\mathrm{Me}$ & 3D-irregular & - & Supercap & $--[143]$ \\
\hline & oxalate & - & & $600-900$ & $450-1450$ & $0.5-1.5$ & $\mathrm{Me}$ & 3D-irregular & - & Supercap & $-[r 444]^{-}$ \\
\hline & glutamate & $\mathrm{NaCl}$ & $\mathrm{N}: 2-8$ & $700-900$ & $400-1000$ & $0.22-0.56$ & $\mathrm{Mi}$ & 3D-irregular & 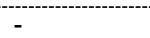 & Supercap & $-[145]$ \\
\hline & $\begin{array}{l}\text { poly(4-styrene } \\
\text { sulfonate) }\end{array}$ & - & & 800 & 1051 & 0.43 & $\mathrm{Mi}+\mathrm{Ma}$ & 3D-irregular & 32 & Li-S battery & $-[1728]^{-}$ \\
\hline & gluconate & - & & $700-900$ & $280-1390$ & $0.21-1$ & $\mathrm{Mi}+\mathrm{Me}$ & nanosheets & $8.5-22$ & Supercap & $-[716]$ \\
\hline & alginate & - & & $\begin{array}{l}800 \\
600\end{array}$ & $\begin{array}{l}1250 \\
270\end{array}$ & 0.63 & $\begin{array}{l}\mathrm{Mi} \\
\mathrm{Mi}\end{array}$ & 3D-irregular & $\begin{array}{l}9 \\
16\end{array}$ & Supercap & $\begin{array}{l}-735]^{-1} \\
{[146]}\end{array}$ \\
\hline & Citrate & Cysteine & $\begin{array}{l}\mathrm{N}: 2, \\
\mathrm{~S}: 0.8\end{array}$ & 800 & 500 & - & $\mathrm{Mi}+\mathrm{Me}$ & $\begin{array}{l}\text { Interconnected } \\
\text { Nanosheets }\end{array}$ & - & $\begin{array}{l}\text { Electro- } \\
\text { oxidation }\end{array}$ & [130] \\
\hline
\end{tabular}




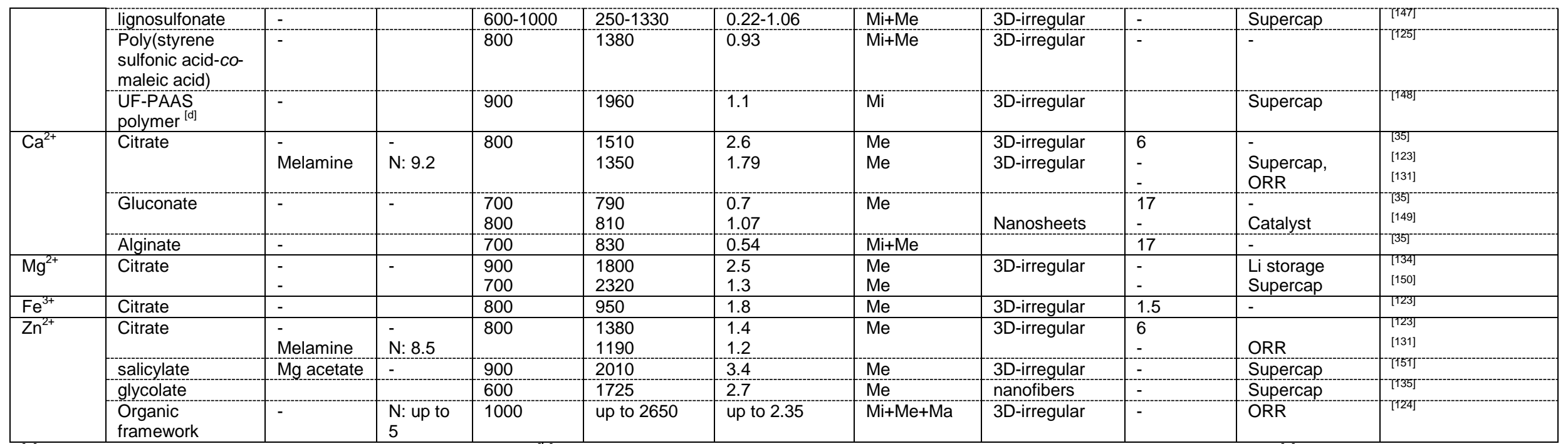

${ }^{[a]}$ Total pore volume determined by $\mathrm{N}_{2}$ physisorption. ${ }^{[\mathrm{b}]} \mathrm{Mi}$ - microporous, $\mathrm{Me}$ - mesoporous and Ma - macroporous pore network. ${ }^{[c]}$ Carbon yield is defined as $\mathrm{g}$ of porous carbon/100 $\mathrm{g}$ of raw carbon precursor. ${ }^{[\mathrm{d}]}$ Urea-formaldehyde polymer interpenetrated with sodium polyacrylate. 


\subsection{Self-activation of biomass}

Considering their low-cost, Earth abundance and sustainability, biomass products constitute the main feedstock for the production of porous carbons. Usually, the methods for producing porous carbons from biomass involve the use of foreign chemical compounds that act as activating agents following either physical or chemical activation routes. However, it has been demonstrated that the production of porous carbons from biomass products can also be carried out without the aid of any foreign substances. Self-activation strategies applied to biomass involve the use of certain substances as activating agents that are part of the biomass or are emitted during its pyrolysis. In general, two different routes can be distinguished in the self-activation of biomass: a) physical selfactivation consisting of the reaction between certain reactive gases emitted during pyrolysis (mainly $\mathrm{CO}_{2}$ and $\mathrm{H}_{2} \mathrm{O}$ ) and the carbonaceous matter; ${ }^{[152-156]}$ and b) chemical self-activation, which is based on the activation power of alkali elements ( $\mathrm{K}$ and $\mathrm{Na}$ ) and alkali earth elements that are part of the biomass. ${ }^{157-}$ ${ }^{160]}$ Both processes are illustrated in Figure 13. It is important to point out that in the case of physical self-activation, the chemical activating action of alkali or alkali earth elements present in the biomass cannot be discarded and, in this case, it is reasonable to assume that both processes (physical and chemical self-activation) will operate together.

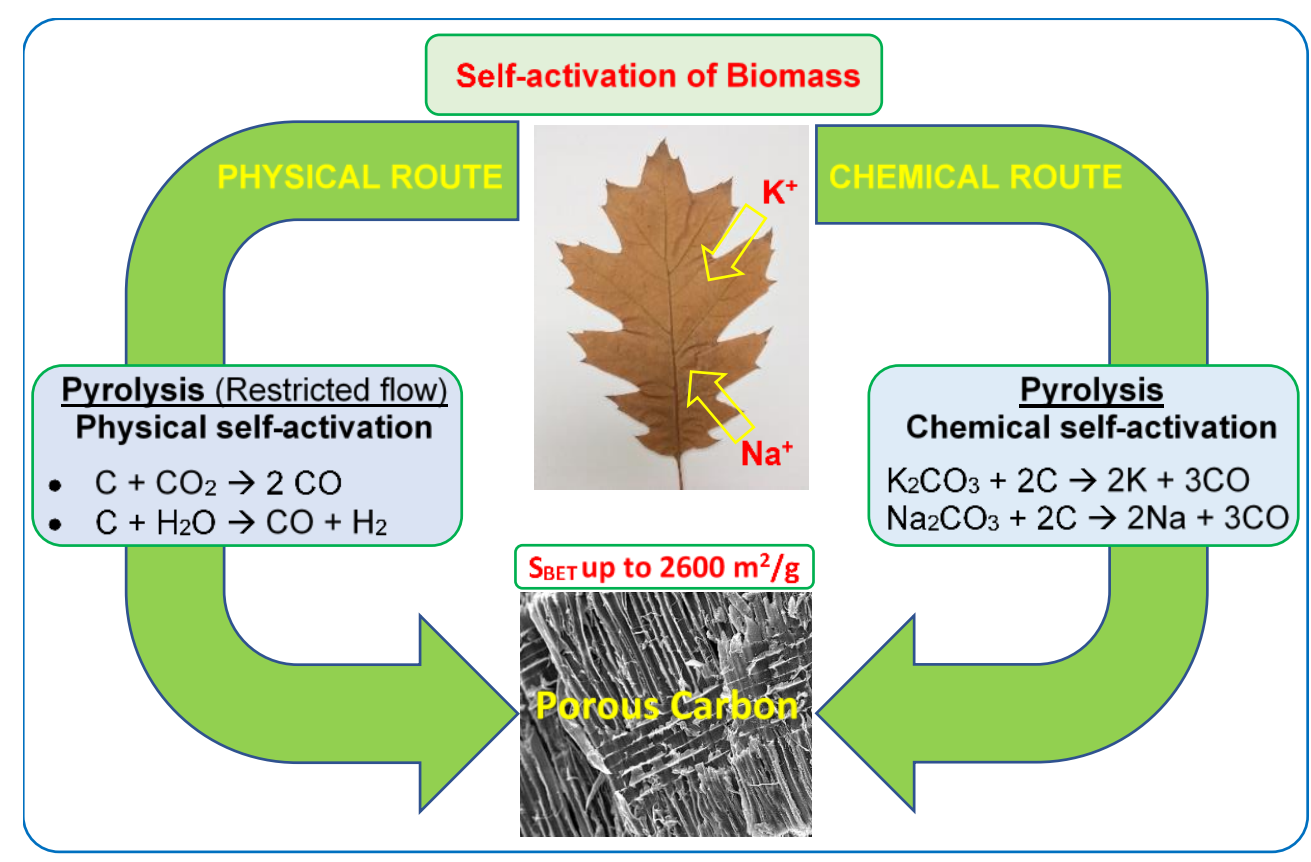

Figure 13. Schematic illustration of the physical and chemical self-activation routes of biomass products.

At this point, it should be noted that examples of carbons produced simply by pyrolysis of biomass that exhibit surprisingly high pore development can be found in the literature. ${ }^{[161-166]}$ In most cases, these apparently anomalous results can only be explained by assuming the occurrence of 
physical or chemical self-activation processes. As an example, Gao et al. reported that just pyrolyzing amaranthus waste led to a carbon with a surprisingly high pore development $\left(1010 \mathrm{~m}^{2} \mathrm{~g}^{-1}, 0.80 \mathrm{~cm}^{3} \mathrm{~g}^{-1}\right.$ and a micromesoporous structure). ${ }^{[161]}$ These textural properties are only understandable by assuming the existence of a chemical self-activation process.

Table 3 summarizes numerous examples of physical and chemical selfactivation for a variety of biomass products.

\subsubsection{Physical self-activation of biomass}

The physical self-activation of biomass is based on the gasification reactions between the carbonaceous matter and the reactive gases evolved during pyrolysis, in particular $\mathrm{CO}_{2}$ and $\mathrm{H}_{2} \mathrm{O}\left[\mathrm{C}+\mathrm{CO}_{2} \rightarrow 2 \mathrm{CO}\right.$ and $\mathrm{C}+\mathrm{H}_{2} \mathrm{O} \rightarrow \mathrm{CO}+$ $\mathrm{H}_{2}$ ]. In order to achieve high pore development, the pyrolysis needs to take place under controlled conditions that favor the gasification reactions between the emitted gases and the carbonaceous matter. Specifically, it requires a reactor with special features that allow partial or complete restriction of the carrier gas flow. In this respect, Bommier et al. showed that simply by restricting the flow of argon during pyrolysis of cellulose from 200 to $10 \mathrm{~mL} \mathrm{~min}^{-1}$, the BET surface area of the derived porous carbon increased from 98 to $2600 \mathrm{~m}^{2} \mathrm{~g}^{-1}$ (Figures 14a, b). ${ }^{[152]}$ In another approach, Xia and Shi carbonized kenaf fibers in a closed reactor (no carrier gas was used in this experiment) obtaining a porous carbon with a high BET surface area up to $2430 \mathrm{~m}^{2} \mathrm{~g}^{-1}$ and a pore volume up to $1.74 \mathrm{~cm}^{3} \mathrm{~g}^{-1} \cdot{ }^{[153]}$ Due to the low reaction rates of the gasification reactions, long reaction times are required and consequently in this case pore development is notably enhanced by long dwell times, as illustrated by the results in Figure 14c. This conclusion is confirmed by the results produced by Smith el al., who investigated the production of porous carbons by means of physical self-activation of ten hardwood species. ${ }^{[156]}$ The production of doped carbons by using this methodology has been investigated by Yang et al., who reported the preparation of $\mathrm{N}, \mathrm{O}$-doped porous carbons $(\mathrm{N}: 2.6$ at \%, O: 7.4 at $\%$ ) with a BET surface area of up to $950 \mathrm{~m}^{2} \mathrm{~g}^{-1}$ and a micro-mesoporous pore network by means of the physical self-activation of hollyhock leaves. ${ }^{[155]}$ 


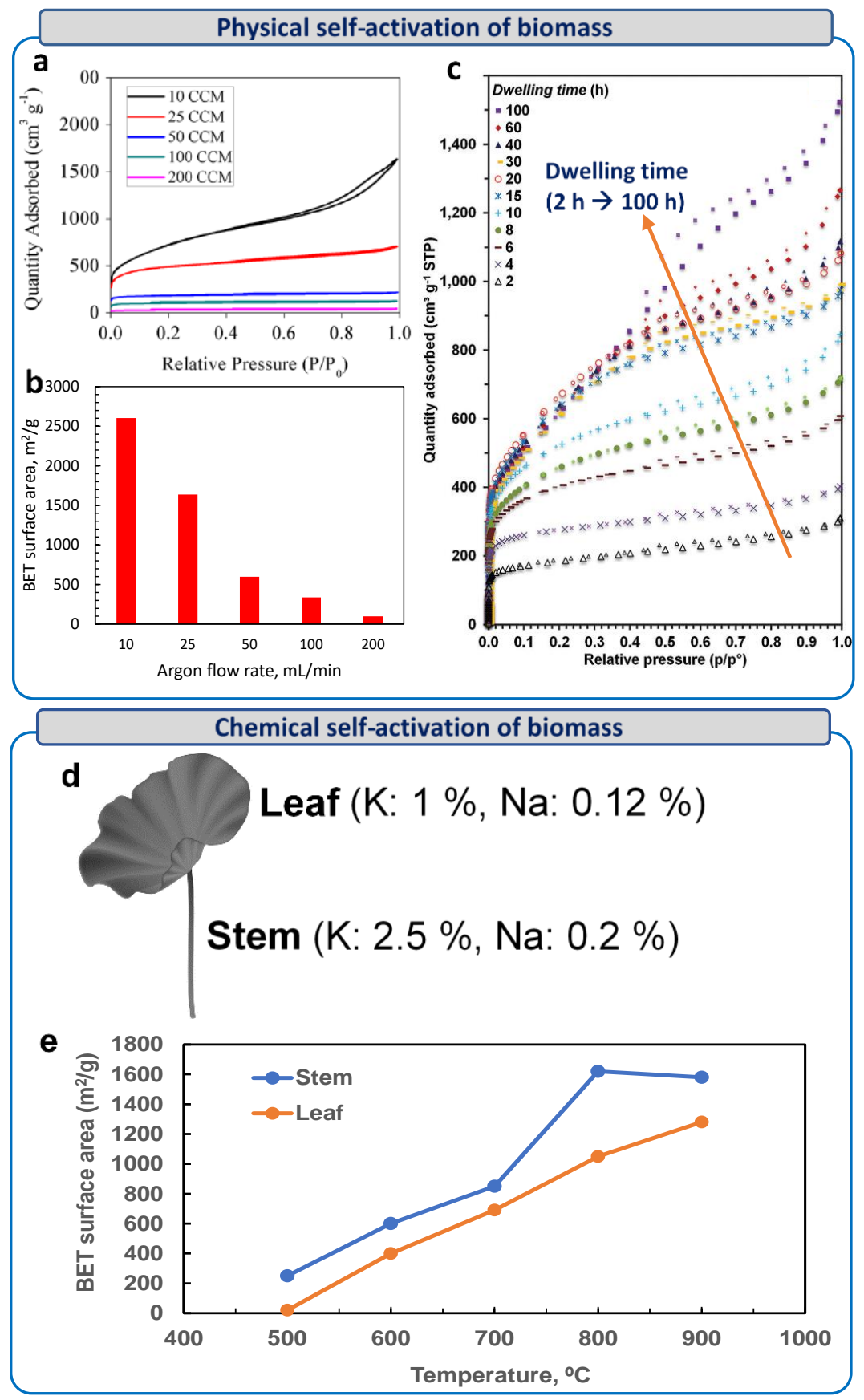

Figure 14. Physical activation of biomass: $a, b)$ effect of the flow rate upon the pore development for the self-activation of cellulose (Reproduced with permission from ref. [152]. Copyright 2015, Elsevier, Ltd), c) effect of dwell time upon the textural development (Reproduced from ref. [153] with permission from the Royal Society of Chemistry). Chemical self-activation of biomass: d) structure of a lotus plant and concentration of $\mathrm{K}$ and $\mathrm{Na}$ in leaf and stem, and e) effect of temperature of self-activation upon surface area of the carbons obtained from stem and leaf of a lotus plant ${ }^{157]}$. 


\subsubsection{Chemical self-activation of biomass}

Biomass products contain abundant amounts of alkali ( $\mathrm{K}$ and Na) elements, as illustrated in Figure 14d. ${ }^{[157]}$ The presence of these elements is the cause of the chemical self-activation. Thus, during pyrolysis, the alkali elements are converted to the corresponding carbonates $\left(\mathrm{K}_{2} \mathrm{CO}_{3}\right.$ and $\left.\mathrm{Na}_{2} \mathrm{CO}_{3}\right)$ that will act as activating agents, as previously described in Sections 2.1 and 3.1 (vide supra). In addition, calcium and magnesium are also transformed into carbonates that subsequently decompose to oxide nanoparticles $(\mathrm{CaO}$ and $\mathrm{MgO})$, which can act as endo-templates, thus contributing to the generation of a certain number of pores.

The chemical self-activation of biomass has been investigated by using a wide variety of products such as kenaf stems, ${ }^{[158]}$ seaweeds, ${ }^{[159,167]}$ wild pokeweed,${ }^{[168]}$ neem leaves, ${ }^{[169]}$ eggplant, ${ }^{[170]}$ tobacco stems, ${ }^{[160]}$ celery,${ }^{[171]}$ pine needles, ${ }^{[172]}$ and lotus stems. ${ }^{[157]}$ In a pioneering work published in 2004, Inagaki et al. carbonized inner cores of kenaf (with a $\mathrm{K}$ content of around $2.7 \%$ ) at $1000 \stackrel{\circ}{\circ} \mathrm{C}$ at a high heating rate $\left(1{ }^{\circ}{ }^{\circ} \mathrm{C} \mathrm{min}^{-1}\right)$ and obtained a porous carbon with a notable surface area of $1400 \mathrm{~m}^{2} \mathrm{~g}^{-1}$, the carbon yield being $13 \% .{ }^{[158]}$ Subsequently, Raymundo-Piñero et al. showed that the pyrolysis of selected seaweeds leads to porous carbons with high surface areas up to $1300 \mathrm{~m}^{2} \mathrm{~g}^{-}$ 1. ${ }^{[159]}$ The key to this approach is the selection of certain types of seaweeds that are rich in carrageenan (a potassium-rich carbohydrate) and in sodium alginate, which ensure the presence of notable amounts of $\mathrm{K}$ and $\mathrm{Na}$. Zhang et al. provided an illustrative example of the chemical self-activation approach. ${ }^{[157]}$ These authors analyzed the chemical composition of lotus stems and leaves and found that the alkali content of $\mathrm{K}$ and $\mathrm{Na}$ in the stems is notably superior to that in the leaves (i.e., K content is $2.5 \%$ in stems vs. $1 \%$ in leaves) (Figure 14d). This means that, although the porous carbon derived from lotus stems carbonized at $800{ }^{\circ} \mathrm{C}$ exhibits a high BET surface area of $1610 \mathrm{~m}^{2} \mathrm{~g}^{-1}$, the carbon sample derived from the leaves has a significantly lower surface area $\left(1040 \mathrm{~m}^{2} \mathrm{~g}^{-1}\right)$ (Figure 14e). Niu et al. proposed an alternative approach consisting of the use of the hydroxyapatite $\left[\mathrm{Ca}_{6}\left(\mathrm{PO}_{4}\right)_{3}\left(\mathrm{CO}_{3}\right)(\mathrm{OH})\right]$ present in animal bones as an activating agent. In this case, the thermal treatment of cattle bones leads to the decomposition of hydroxyapatite (at $\mathrm{T}>750^{\circ} \mathrm{O}$ ) giving rise to several products that act as activating agents (i.e., $\mathrm{CO}_{2}, \mathrm{H}_{2} \mathrm{O}$ and also $\mathrm{CaO}$ nanoparticles). The carbon produced at $1100 \stackrel{\circ}{ } \mathrm{C}$ has a high pore development with a BET surface area of $2100 \mathrm{~m}^{2} \mathrm{~g}^{-1}$ and a porosity made up almost exclusively of mesopores. ${ }^{[173]}$

By selecting biomass products with a large content of heteroatoms (i.e., $\mathrm{N}, \mathrm{S}$, etc.), doped porous carbons can be produced by self-activation as has been demonstrated by $\mathrm{He}$ et al., who produced $\mathrm{N}$-doped porous carbons $\left(\mathrm{S}_{\mathrm{BET}}\right.$ up to $1190 \mathrm{~m}^{2} \mathrm{~g}^{-1}$ ) by means of the chemical self-activation of $\mathrm{N}$-rich biomass such as celery plants. ${ }^{[171]}$ On similar lines, Liu et al. prepared nitrogen-rich mesoporous carbons with up to $8 \% \mathrm{~N}$ simply by pyrolyzing shrimp skin at temperatures in the $600-900 \stackrel{\circ}{-} \mathrm{C}$ range ${ }^{[162]}$ 
Table 3. Porous carbons prepared by self-activation of biomass products.

\begin{tabular}{|c|c|c|c|c|c|c|c|}
\hline Biomass & $\mathrm{T}_{\text {pyrolysis }}\left({ }^{\circ} \mathrm{C}\right)$ & $\begin{array}{c}\mathrm{S}_{\mathrm{BET}} \\
\left(\mathrm{m}^{2} \mathrm{~g}^{-1}\right)\end{array}$ & $\begin{array}{l}\text { Pore volume } \\
\left(\mathrm{cm}^{3} \mathrm{~g}^{-1}\right)^{[\mathrm{a}]}\end{array}$ & $\begin{array}{c}\text { Pore } \\
\text { structure }^{[b]}\end{array}$ & $\begin{array}{c}\text { Carbon } \\
\text { yield }(\%)^{[c]}\end{array}$ & Application & Reference \\
\hline \multicolumn{8}{|c|}{ Physical self-activation } \\
\hline Cellulose & 1100 & 2600 & 2.1 & $\mathrm{Me}$ & 1.6 & Supercap & {$[152]$} \\
\hline Kenaf core & $900-1100$ & $500-2400$ & $0.34-1.7$ & $\mathrm{Me}$ & $16-2.8$ & - & {$[153]$} \\
\hline Rice husk & 800 & 530 & 0.33 & $\mathrm{Mi}+\mathrm{Me}$ & - & Supercap & [154] \\
\hline Hollyhock (leaves) & 850 & 950 & 0.6 & $\mathrm{Mi}+\mathrm{Me}$ & 25 & Supercap & [155] \\
\hline Wood (Afromosia) & 1050 & $>2500$ & 1.4 & $\mathrm{Me}$ & - & - & {$[156]$} \\
\hline \multicolumn{8}{|c|}{ Chemical self-activation } \\
\hline Kenaf core & 1000 & 1400 & 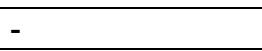 & $\mathrm{Mi}$ & 13 & - & {$[158]$} \\
\hline $\begin{array}{l}\text { Seaweed } \\
\text { Lessonia nigrescens }\end{array}$ & 900 & 1300 & 0.53 & $\mathrm{Mi}+\mathrm{Me}$ & 15 & Supercap & $\begin{array}{l}{[159]} \\
{[167]}\end{array}$ \\
\hline Pokeweed & 900 & 720 & 0.56 & $\mathrm{Me}$ & 20 & Phenol removal & {$[168]$} \\
\hline Neem leaves & 1000 & 1230 & - & $\mathrm{Mi}+\mathrm{Me}$ & - & Supercap & [169] \\
\hline Eggplant & 1000 & 950 & - & $\mathrm{Mi}+\mathrm{Me}$ & - & Supercap & {$[170]$} \\
\hline Tobacco stems & 800 & 1750 & 0.95 & $\mathrm{Mi}$ & - & Supercap & [160] \\
\hline Amaranthus & 900 & 1010 & 0.80 & $\mathrm{Mi}+\mathrm{Me}$ & & ORR & [161] \\
\hline $\begin{array}{l}\text { Lotus stem } \\
\text { Letucce stem } \\
\text { Celery stem }\end{array}$ & 800 & $\begin{array}{l}1610 \\
1075 \\
1230 \\
\end{array}$ & $\begin{array}{l}0.8 \\
-\end{array}$ & $\mathrm{Mi}$ & 13 & $\begin{array}{l}\text { Supercap } \\
\text { Supercap } \\
\text { Supercap }\end{array}$ & {$[15 /]$} \\
\hline Cattle bones & 1100 & 2100 & 1.8 & $\mathrm{Me}$ & - & $\begin{array}{l}\text { Supercap, Li-ion } \\
\text { battery }\end{array}$ & {$[1 / 3]$} \\
\hline Shrimp skin & 800 & 510 & 0.71 & $\mathrm{Me}$ & - & Na-ion battery & {$[163]$} \\
\hline Pine needles & 1000 & 780 & 0.5 & $\mathrm{Mi}+\mathrm{Me}$ & - & Supercap & {$[1 / 2]$} \\
\hline Celery stem & 900 & 1190 & 0.64 & $\mathrm{Me}$ & $>30$ & Supercap & {$[171]$} \\
\hline
\end{tabular}

${ }^{[a]}$ Total pore volume determined by $\mathrm{N}_{2}$ physisorption. ${ }^{[\mathrm{b}]} \mathrm{Mi}$ - microporous, Me - mesoporous and Ma - macroporous pore network. ${ }^{[\mathrm{c}]}$ Carbon yield is defined as $\mathrm{g}$ of porous carbon $/ 100 \mathrm{~g}$ of raw carbon precursor. 


\section{Summary and outlook}

There is no doubt that porous carbons play a key role in many emergent applications, including electrochemical energy storage/production, carbon capture and gas storage (e.g., $\mathrm{H}_{2}$ or $\mathrm{CH}_{4}$ ), and still play a leading role in traditional applications such as catalysis and water/gas purification. Traditional activation processes, especially chemical activation procedures, are based on the use of (highly) corrosive, toxic substances. This not only poses significant restrictions on equipment and safety protocols, but also represents a serious environmental threat. This has spurred the search for greener chemical activating agents, as well as the development of novel activation procedures. However, it should be noted that potassium hydroxide is still massively used at the laboratory scale, as it allows the synthesis of high-performing activated carbons with advanced properties. It is the authors' opinion that future efforts are mandatory from the scientific community to replace potassium hydroxide, as its use is quite unrealistic from the industrial point of view.

In the search for greener activating agents, potassium-based carbonates, bicarbonates and organic salts have been explored. What they have in common is that the actual activating agent is potassium carbonate, which is also the main reaction product during potassium hydroxide activation. Even though the pore development achieved with these activating agents is normally lower than that achieved via $\mathrm{KOH}$ activation, they stand out for allowing higher activation yields and preserving the particle morphology of the precursor. Furthermore, it has been shown that the rational design of the activation procedure allows the production of materials with a pore development similar to that of benchmark $\mathrm{KOH}$-derived ACs. Thus, confinement of the reactants in an inert medium such as $\mathrm{KCl}$, which forms a eutectic mixture with $\mathrm{K}_{2} \mathrm{CO}_{3}$ below the temperature at which the redox reaction with carbon takes place, enhances the reactivity between the carbonaceous matter and $\mathrm{K}_{2} \mathrm{CO}_{3}$. An additional important advantage of this confined activation is the increase in the yield. In fact, the main disadvantage of conventional chemical and physical activation processes lies in the low carbon yields, especially for high pore developments. Therefore, future efforts must be targeted at developing strategies that enhance the yield of activation processes. In this regard, salt melt approaches are very promising. Contrary to potassium-based carbonates/bicarbonates/organic salts, their sodium-based counterparts have been little-used as activating agents, as they are less effective than potassium-based agents.

It is worth noting the role that nitrogen heteroatoms have on porosity development, no matter whether they come from a foreign additive (e.g., melamine, urea, etc.) or they form part of the carbon precursor. Porous carbons with ultra-large BET surface areas in excess of $3000 \mathrm{~m}^{2} \mathrm{~g}^{-1}$ and pore volumes above $2 \mathrm{~cm}^{3} \mathrm{~g}^{-1}$ have been obtained. Additionally, these materials normally exhibit a bimodal micro-mesoporous structure with a large proportion of mesopores, in contrast to $\mathrm{K}_{2} \mathrm{CO}_{3}$ or $\mathrm{KOH}$-derived $\mathrm{ACs}$ which have a predominantly microporous pore network. However, highly toxic potassium cyanide is obtained as a by-product in these activation processes, which speaks against the suitability of these activation strategies. Therefore, novel methodologies for tuning the pore size distribution of activated carbons must be 
sought. Indeed, control over the pore size distribution of activated carbons is still a challenge to be overcome and a key aspect in many applications (e.g., supercapacitors or gas storage).

Recently, potassium/sodium sulfates and especially thiosulfates have been shown to be powerful activating agents when the activation process is carefully engineered. Confinement of the activation reactions in eutectic mixtures of salts (e.g., $\mathrm{LiCl}$ and $\mathrm{KCl}$ ) or just in a salt melting below the synthesis temperature (e.g., $\mathrm{KCl}$ melts at $770^{\circ} \mathrm{C}$ ), reinforces the contact between the solid carbonaceous matter and the $\mathrm{Na}_{2} \mathrm{SO}_{4}-\mathrm{Na}_{2} \mathrm{~S}$ liquid system, thereby enhancing the reactivity. Furthermore, this confinement substantially improves the carbon yield, enhancing the efficiency of the synthesis process.

As an alternative to the use of foreign activating compounds, there has been increasing interest in self-activation techniques, where the porogenic action is performed exclusively by substances that are part of the carbon precursor. They are not only greener, but also low-cost, simpler, less-time consuming, and generate less waste. Indeed, the production of the porous carbon can be performed in one step by a standard carbonization process. The raw materials appropriate as carbon precursors need to include one of the following elements in their composition: alkali metals $(\mathrm{K}, \mathrm{Na})$, alkali earth metals $(\mathrm{Ca}, \mathrm{Mg}$ ) or other elements such as $\mathrm{Fe}$ o $\mathrm{Zn}$. They can be organic or polymeric salts or even better, biomass. The self-activation involves three pore generation mechanisms: i) chemical activation (oxidation of carbon by carbonates or oxides), ii) physical activation (gasification of carbon by $\mathrm{CO}_{2}$ ) and iii) endotemplate processes (after removal of the inorganic phases embedded in the carbon matrix). Interestingly, one can envisage that an effective activation of biomass can be carried out by means of a methodology that combines the advantages of physical and chemical self-activation processes. For example, by selecting biomass products with high content of alkali and alkali earth elements and by performing the pyrolysis under restricted flow conditions, the easy, sustainable, low-cost production of highly porous carbons would be possible.

\section{Acknowledgments}

This research work was supported by projects RTI2018-093712-B-I00 (MCIU/AEI/FEDER, UE) and IDI/2018/000148 (regional GRUPIN2018).

\section{Conflict of Interest}

The authors declare no conflicts of interest.

Keywords: chemical activation; microporous materials; porous carbons; sustainable chemistry.

\section{References}

[1] H. Marsh, F. Rodríguez-Reinoso, Activated Carbon, Elsevier Science Ltd, 
Oxford, 2006.

[2] P. Hadi, M. Xu, C. Ning, C. Sze Ki Lin, G. McKay, Chem. Eng. J. 2015, 260, 895.

[3] X. Zhang, B. Gao, A. E. Creamer, C. Cao, Y. Li, J. Hazard. Mater. 2017, $338,102$.

[4] H. J. Schröter, Gas Sep. Purif. 1993, 7, 247.

[5] J. Liu, E. M. Calverley, M. H. McAdon, J. M. Goss, Y. Liu, K. C. Andrews, T. D. Wolford, D. E. Beyer, C. S. Han, D. A. Anaya, R. P. Golombeski, C.

F. Broomall, S. Sprague, H. Clements, K. F. Mabe, Carbon 2017, 123, 273.

[6] K. V. Kumar, K. Preuss, M. M. Titirici, F. Rodríguez-Reinoso, Chem. Rev. 2017, 117, 1796.

[7] K. M. Thomas, Catal. Today 2007, 120, 389.

[8] M. Sevilla, R. Mokaya, Energy Environ. Sci., 2014, 7, 1250.

[9] M. Sevilla, G. A. Ferrero, A. B. Fuertes, Nanoporous Materials for Gas Storage, Springer, Singapore, 2019, pp. 287-330.

[10] G. Singh, K. S. Lakhi, S. Sil, S. V Bhosale, I. Kim, K. Albahily, A. Vinu, Carbon 2019, 148, 164.

[11] S. De, A. M. Balu, J. C. van der Waal, R. Luque, ChemCatChem 2015, 7, 1608.

[12] F. Beguin, E. Frackowiak, Carbons for Electrochemical Energy Storage and Conversion Systems, CRC Press, 2009.

[13] W. Long, B. Fang, A. Ignaszak, Z. Wu, Y. J. Wang, D. Wilkinson, Chem. Soc. Rev. 2017, 46, 7176.

[14] J. Wang, P. Nie, B. Ding, S. Dong, X. Hao, H. Dou, X. Zhang, J. Mater. Chem. A 2017, 5, 2411.

[15] H. Lu, X. S. Zhao, Sustain. Energy Fuels 2017, 1, 1265.

[16] F. Rodríguez-Reinoso, M. Molina-Sabio, M. T. González, Carbon 1995, 33, 15.

[17] J. Rodríguez-Mirasol, T. Cordero, J. J. Rodríguez, Energy and Fuels 1993, 7, 133.

[18] T. Otowa, R. Tanibata, M. Itoh, Gas Sep. Purif. 1993, 7, 241.

[19] I. Moulefera, F. J. García-Mateos, A. Benyoucef, J. M. Rosas, J. Rodríguez-Mirasol, T. Cordero, Front. Mater. 2020, 7, 153.

[20] J. Wang, S. Kaskel, J. Mater. Chem. 2012, 22, 23710.

[21] H. Chen, H. Wei, N. Fu, W. Qian, Y. Liu, H. Lin, S. Han, J. Mater. Sci. 2018, 53, 2669.

[22] M. Sevilla, R. Mokaya, A. B. Fuertes, Energy Environ. Sci. 2011, 4, 2930.

[23] G. Sethia, A. Sayari, Carbon 2016, 99, 289.

[24] H. M. Coromina, D. A. Walsh, R. Mokaya, J. Mater. Chem. A 2016, 4, 280.

[25] M. Cox, R. Mokaya, Sustain. Energy Fuels 2017, 1, 1414.

[26] J. Liu, X. Liu, Y. Sun, C. Sun, H. Liu, L. A. Stevens, K. Li, C. E. Snape, Adv. Sustain. Syst. 2018, 2, 1700115.

[27] J. Yin, W. Zhang, N. A. Alhebshi, N. Salah, H. N. Alshareef, Small Methods 2020, 4, 1900853.

[28] Z. Li, Y. Huang, L. Yuan, Z. Hao, Y. Huang, Carbon 2015, 92, 41.

[29] G. Li, Z. Yang, Z. Yin, H. Guo, Z. Wang, G. Yan, Y. Liu, L. Li, J. Wang, J. Mater. Chem. A 2019, 7, 15541.

[30] S. Zhou, L. Zhou, Y. Zhang, J. Sun, J. Wen, Y. Yuan, J. Mater. Chem. A 
2019, 7, 4217.

[31] J. Deng, M. Li, Y. Wang, Green Chem. 2016, 18, 4824.

[32] Z. Bi, Q. Kong, Y. Cao, G. Sun, F. Su, X. Wei, X. Li, A. Ahmad, L. Xie, C. M. Chen, J. Mater. Chem. A 2019, 7, 16028.

[33] D. W. McKee, Fuel 1983, 62, 170.

[34] J. Hayashi, T. Horikawa, I. Takeda, K. Muroyama, F. Nasir Ani, Carbon 2002, 40, 2381.

[35] M. Sevilla, A. B. Fuertes, J. Mater. Chem. A 2013, 1, 13738.

[36] E. Raymundo-Piñero, P. Azaïs, T. Cacciaguerra, D. Cazorla-Amorós, A. Linares-Solano, F. Béguin, Carbon 2005, 43, 786.

[37] M. Sevilla, A. B. Fuertes, ChemSusChem 2016, 9, 1880.

[38] J. Deng, T. Xiong, H. Wang, A. Zheng, Y. Wang, ACS Sustain. Chem. Eng. 2016, 4, 3750.

[39] M. A. Lillo-Ródenas, D. Cazorla-Amorós, A. Linares-Solano, Carbon 2003, 41, 267.

[40] A. S. Mestre, C. Freire, J. Pires, A. P. Carvalho, M. L. Pinto, J. Mater. Chem. A 2014, 2, 15337.

[41] A. S. Mestre, F. Hesse, C. Freire, C. O. Ania, A. P. Carvalho, J. Colloid Interface Sci. 2019, 536, 681.

[42] E. Santos-Clotas, A. Cabrera-Codony, B. Ruiz, E. Fuente, M. J. Martín, Bioresour. Technol. 2019, 275, 207.

[43] N. F. Sylla, N. M. Ndiaye, B. D. Ngom, D. Momodu, M. J. Madito, B. K. Mutuma, N. Manyala, Sci. Rep. 2019, 9, 13673.

[44] F. Zhang, T. Liu, G. Hou, T. Kou, L. Yue, R. Guan, Y. Li, Nano Res. 2016, 9, 2875.

[45] N. Diez, G. A. Ferrero, A. B. Fuertes, M. Sevilla, Batter. Supercaps 2019, 2, 701.

[46] S. M. Anisuzzaman, C. G. Joseph, D. Krishnaiah, A. Bono, E. Suali, S. Abang, L. M. Fai, Water Resour. Ind. 2016, 16, 29.

[47] M. Jagtoyen, F. Derbyshire, Carbon 1998, 36, 1085.

[48] N. Diez, G. A. Ferrero, M. Sevilla, A. B. Fuertes, J. Mater. Chem. A 2019, 7, 14280.

[49] N. Tsubouchi, M. Nishio, Y. Mochizuki, Appl. Surf. Sci. 2016, 371, 301.

[50] A. B. Fuertes, M. Sevilla, ChemSusChem 2015, 8, 1049.

[51] A. B. Fuertes, M. Sevilla, Carbon 2015, 94, 41.

[52] C. Schneidermann, N. Jäckel, S. Oswald, L. Giebeler, V. Presser, L. Borchardt, ChemSusChem 2017, 10, 2416.

[53] C. Schneidermann, C. Kensy, P. Otto, S. Oswald, L. Giebeler, D. Leistenschneider, S. Grätz, S. Dörfler, S. Kaskel, L. Borchardt, ChemSusChem 2019, 12, 310.

[54] M. Sevilla, P. Valle-Vigon, A. B. Fuertes, Adv. Funct. Mater. 2011, 21, 2781.

[55] L. Wei, M. Sevilla, A. B. Fuertes, R. Mokaya, G. Yushin, Adv. Funct. Mater. 2012, 22, 827.

[56] J. Deng, T. Xiong, F. Xu, M. Li, C. Han, Y. Gong, H. Wang, Y. Wang, Green Chem. 2015, 17, 4053.

[57] M. Zhou, Y. Lin, H. Xia, X. Wei, Y. Yao, X. Wang, Z. Wu, Nano-Micro Lett. 2020, $12,58$.

[58] P. Hong, X. Liu, X. Zhang, S. Peng, Z. Wang, Y. Yang, R. Zhao, Y. Wang, Int. J. Energy Res. 2020, 44, 988. 
[59] C. Zhao, S. Zhang, N. Sun, H. Zhou, G. Wang, Y. Zhang, H. Zhang, H. Zhao, Environ. Sci. Water Res. Technol. 2019, 5, 1054.

[60] Y. Wang, R. Ma, R. Xiao, Q. Wu, C. Wang, Z. Wang, J. Sep. Sci. 2017, 40, 2451.

[61] A. K. Mondal, K. Kretschmer, Y. Zhao, H. Liu, C. Wang, B. Sun, G. Wang, Chem. A Eur. J. 2017, 23, 3683.

[62] S. Li, M. Wang, Y. Yao, T. Zhao, L. Yang, F. Wu, ACS Appl. Mater. Interfaces 2019, 11, 34997.

[63] Y. Liu, M. Hu, W. Xu, X. Wu, J. Jiang, Front. Chem. 2019, 7, 786.

[64] Z. Chen, J. Sun, R. Bao, X. Sun, J. Zhang, L. Hou, C. Yuan, ACS Sustain. Chem. Eng. 2019, 7, 779.

[65] D. Xu, Y. Tong, T. Yan, L. Shi, D. Zhang, ACS Sustain. Chem. Eng. 2017, $5,5810$.

[66] M. Tian, Y. Zhu, D. Zhang, M. Wang, Y. Chen, Y. Yang, S. Gao, Nano Energy 2019, 64, 103940.

[67] J. Qi, W. Zhang, L. Xu, Chem. A Eur. J. 2018, 24, 18097.

[68] W. Zhang, J. Qi, P. Bai, H. Wang, L. Xu, New J. Chem. 2019, 43, 10878.

[69] S. Zhao, T. Yan, Z. Wang, J. Zhang, L. Shi, D. Zhang, RSC Adv. 2017, 7, 4297.

[70] H. Cheng, Y. Bian, F. Wang, X. Jiang, R. Ji, C. Gu, X. Yang, Y. Song, Bioresour. Technol. 2019, 284, 1.

[71] F. O. Ochai-Ejeh, D. Y. Momodu, M. J. Madito, A. A. Khaleed, K. O. Oyedotun, S. C. Ray, N. Manyala, AIP Adv. 2018, 8, 055208.

[72] K. K. Lee, T. L. Church, N. Hedin, ACS Appl. Energy Mater. 2018, 1, 3815.

[73] A. Ilnicka, J. P. Lukaszewicz, Mater. Sci. Eng. B 2015, 201, 66.

[74] J. Fujiki, K. Yogo, Chem. Commun. 2016, 52, 186.

[75] P. J. M. Carrott, M. M. L. Ribeiro Carrott, P. A. M. Mourão, J. Anal. Appl. Pyrolysis 2006, 75, 120.

[76] W. Tian, H. Zhang, X. Duan, H. Sun, M. O. Tade, H. M. Ang, S. Wang, ACS Appl. Mater. Interfaces 2016, 8, 7184.

[77] T. Ouyang, T. Zhang, H. Wang, F. Yang, J. Yan, K. Zhu, K. Ye, G. Wang, L. Zhou, K. Cheng, D. Cao, Chem. Eng. J. 2018, 352, 459.

[78] Y. Liu, G. Dai, L. Zhu, S. Wang, ChemElectroChem 2019, 6, 646.

[79] J. Hayashi, A. Kazehaya, K. Muroyama, A. P. Watkinson, Carbon 2000, 38, 1873.

[80] J. W. Kim, H. G. Lee, Metall. Mater. Trans. B 2001, 32, 17.

[81] N. Tsubouchi, M. Nishio, Y. Shinohara, J. Bud, Y. Mochizuki, Fuel Process. Technol. 2018, 176, 76.

[82] M. Sevilla, G. A. Ferrero, A. B. Fuertes, Carbon 2017, 114, 50.

[83] M. Sevilla, A. S. M. Al-Jumialy, A. B. Fuertes, R. Mokaya, ACS Appl. Mater. Interfaces 2018, 10, 1623.

[84] J. Ludwinowicz, M. Jaroniec, Carbon 2015, 82, 297.

[85] J. S. Wei, S. Wan, P. Zhang, H. Ding, X. B. Chen, H. M. Xiong, S. Gao, X. Wei, New J. Chem. 2018, 42, 6763.

[86] J. Li, Q. Jiang, L. Wei, L. Zhong, X. Wang, J. Mater. Chem. A 2020, 8, 1469.

[87] H. Lin, C. Xu, Q. Wang, J. Wu, Y. Wang, Y. Zhang, G. Fan, Int. J. Hydrogen Energy 2019, 44, 21527.

[88] Q. Jiang, Y. Wang, Y. Gao, Y. Zhang, Environ. Sci. Pollut. Res. 2019, 26, 
30268.

[89] M. Sevilla, G. A. Ferrero, A. B. Fuertes, Chem. Mater. 2017, 29, 6900.

[90] L. Xie, L. Kang, Y. Li, M. Cui, B. Chang, H. Jiang, L. Gao, X. Wang, S. Yun, Nano 2017, 12, 1750040.

[91] Q. Li, X. Wu, Y. Zhao, Z. Miao, L. Xing, J. Zhou, J. Zhao, S. Zhuo, ChemElectroChem 2018, 5, 1606.

[92] J. Zhang, W. Zhang, M. Han, J. Pang, Y. Xiang, G. Cao, Y. Yang, Microporous Mesoporous Mater. 2018, 270, 204.

[93] G. Singh, I. S. Ismail, C. Bilen, D. Shanbhag, C. I. Sathish, K. Ramadass, A. Vinu, Appl. Energy 2019, 255, 113831.

[94] X. Hu, Y. H. Wang, B. Ding, X. Wu, J. Alloys Compd. 2019, 785, 110.

[95] Y. Wang, B. Ding, D. Guo, X. Wu, Microporous Mesoporous Mater. 2019, $282,114$.

[96] L. Guan, L. Pan, T. Peng, T. Qian, Y. Huang, X. Li, C. Gao, Z. Li, H. Hu, M. Wu, Carbon 2019, 152, 537.

[97] B. Liu, H. Li, X. Ma, R. Chen, S. Wang, L. Li, RSC Adv. 2018, 8, 38965.

[98] Y. Jiang, J. Yan, X. Wu, D. Shan, Q. Zhou, L. Jiang, D. Yang, Z. Fan, J. Power Sources 2016, 307, 190.

[99] P. Zhang, M. Liu, S. Liu, J. Mater. Sci. Mater. Electron. 2020, 31, 3519.

[100] W. Xiong, G. Yang, T. H. Yang, S. Liu, Y. Jung, Bull. Korean Chem. Soc. 2017, 38, 350.

[101] A. C. Dassanayake, M. Jaroniec, J. Mater. Chem. A 2017, 5, 19456.

[102] A. B. Fuertes, G. A. Ferrero, N. Diez, M. Sevilla, ACS Sustain. Chem. Eng. 2018, 6, 16323.

[103] M. Sevilla, N. Diez, G. A. Ferrero, A. B. Fuertes, Energy Storage Mater. 2019, 18, 356.

[104] X. Liu, M. Antonietti, Adv. Mater. 2013, 25, 6284.

[105] X. Liu, M. Antonietti, Carbon 2014, 69, 460.

[106] M. Sevilla, J. Carro-Rodríguez, N. Diez, A. B. Fuertes, Sci. Rep. 2020, 10, 4866.

[107] N. Diez, M. Sevilla, A. B. Fuertes, ACS Appl. Energy Mater. 2020, 3, 3397.

[108] N. Diez, G. A. Ferrero, M. Sevilla, A. B. Fuertes, Sustain. Energy Fuels 2019, 3, 3498.

[109] W. Tian, H. Zhang, H. Sun, M. O. Tadé, S. Wang, Chem. Eng. J. 2018, $347,432$.

[110] J. Zhang, W. Zhang, M. Han, J. Pang, J. Mater. Sci. Mater. Electron. 2018, 29, 4639.

[111] A. Srivastava, P. Singh, V. G. Gunjikar, C. I. Jose, Thermochim. Acta 1984, 76, 249.

[112] A. Marcilla, A. Gómez, M. Beltrán, D. Berenguer, I. Martínez, I. Blasco, J. Anal. Appl. Pyrolysis 2017, 125, 144.

[113] M. Sevilla, A. B. Fuertes, ACS Nano 2014, 8, 5069.

[114] B. Chang, L. Wang, W. Shi, Y. Chai, S. Zhang, B. Yang, Sustain. Energy Fuels 2020, 4, 2527.

[115] B. Yang, J. Chen, S. Lei, R. Guo, H. Li, S. Shi, X. Yan, Adv. Energy Mater. 2018, 8, 1702409.

[116] A. B. Fuertes, M. Sevilla, ACS Appl. Mater. Interfaces 2015, 7, 4344.

[117] W. Yang, W. Yang, F. Ding, L. Sang, Z. Ma, G. Shao, Carbon 2017, 111, 419. 
[118] J. Lee, Y. A. Lee, C. Y. Yoo, J. J. Yoo, R. Gwak, W. K. Cho, B. Kim, H. Yoon, Microporous Mesoporous Mater. 2018, 261, 119.

[119] Y. He, X. Zhuang, C. Lei, L. Lei, Y. Hou, Y. Mai, X. Feng, Nano Today 2019, 24, 103.

[120] M. Sevilla, G. A. Ferrero, N. Diez, A. B. Fuertes, Carbon 2018, 131, 193.

[121] D. Li, X. Ren, Q. Ai, Q. Sun, L. Zhu, Y. Liu, Z. Liang, R. Peng, P. Si, J. Lou, J. Feng, L. Ci, Adv. Energy Mater. 2018, 8, 1802386.

[122] N. Khan, D. Dollimore, K. Alexander, F. W. Wilburn, Thermochim. Acta 2001, 367, 321.

[123] G. A. Ferrero, M. Sevilla, A. B. Fuertes, Carbon 2015, 88, 239.

[124] L. Tong, L.L. Zhang, Y.C. Wang, L.Y. Wan, Q.-Q. Yan, C. Hua, C.J. Jiao, Z.Y. Zhou, Y.W. Ding, B. Liu, H.W. Liang, ACS Appl. Mater. Interfaces 2020, 12, 25211.

[125] D. Hines, A. Bagreev, T. J. Bandosz, Langmuir 2004, 20, 3388.

[126] P. Yadav, A. Banerjee, S. Unni, J. Jog, S. Kurungot, S. Ogale, ChemSusChem 2012, 5, 2159.

[127] D. Puthusseri, V. Aravindan, S. Madhavi, S. Ogale, Energy Environ. Sci. 2014, 7, 728.

[128] A. D. Roberts, X. Li, H. Zhang, Carbon 2015, 95, 268.

[129] A. B. Fuertes, G. A. Ferrero, M. Sevilla, J. Mater. Chem. A 2014, 2, 14439.

[130] W. Gao, X. Feng, T. Zhang, H. Huang, J. Li, W. Song, ACS Appl. Mater. Interfaces 2014, 6, 19109.

[131] G. A. Ferrero, A. B. Fuertes, M. Sevilla, M.M. Titirici, Carbon 2016, 106, 179.

[132] G. A. Ferrero, N. Diez, M. Sevilla, A. B. Fuertes, Micropor. Mesopor. Mater. 2019, 278, 280.

[133] Y. Wang, H. Wang, H. Wang, M. Zhang, X. Liang, K. Xia, Y. Zhang, ACS Appl. Mater. Interfaces 2019, 11, 20272.

[134] T. Tsumura, A. Arikawa, T. Kinumoto, Y. Arai, T. Morishita, H. Orikasa, M. Inagaki, M. Toyoda, Mater. Chem. Phys. 2014, 147, 1175.

[135] W. Li, F. Zhang, Y. Dou, Z. Wu, H. Liu, X. Qian, D. Gu, Y. Xia, B. Tu, D. Zhao, Adv. Energy Mater. 2011, 1, 382.

[136] H. Luo, Y. Yang, X. Zhao, J. Zhang, Y. Chen, Electrochim. Acta 2015, 169, 13.

[137] B. Adeniran, E. Masika, R. Mokaya, J. Mater. Chem. A 2014, 2, 14696.

[138] J. D. Atkinson, M. J. Rood, Microporous Mesoporous Mater. 2012, 160, 174.

[139] Y. Zhu, H. Cui, X. Meng, J. Zheng, P. Yang, L. Li, Z. Wang, S. Jia, Z. Zhu, ACS Appl. Mater. Interfaces 2016, 8, 6481.

[140] N. Wang, Y. Wang, X. Xu, T. Liao, Y. Du, Z. Bai, S. Dou, ACS Appl. Mater. Interfaces 2018, 8, 6481.

[141] B. Xu, H. Duan, M. Chu, G. Cao, Y. Yang, J. Mater. Chem. A 2013, 1, 4565.

[142] B. Xu, D. Zheng, M. Jia, G. Cao, Y. Yang, Electrochim. Acta 2013, 98, 176.

[143] S. Yu, N. Sun, L. Hu, L. Wang, Q. Zhu, Y. Guan, B. Xu, J. Power Sources 2018, 405, 132.

[144] H. Luo, Y. Yang, Y. Sun, D. Chen, X. Zhao, D. Zhang, J. Zhang, J. Appl. Electrochem. 2015, 45, 839. 
[145] W. Qian, J. Zhu, Y. Zhang, X. Wu, F. Yan, Small 2015, 11, 4959.

[146] E. Raymundo-Piñero, F. Leroux, F. Béguin, Adv. Mater. 2006, 18, 1877.

[147] J. Pang, W. Zhang, J. Zhang, G. Cao, M. Han, Y. Yang, Green Chem. 2017, 19, 3916.

[148] J. K. Guo, J. Liu, L. Bin Kong, ChemElectroChem 2020, 7, 2592.

[149] T. Yang, W. Li, M. Su, Y. Liu, M. Liu, New J. Chem. 2020, 44, 7968.

[150] J. Zhou, X. Yuan, W. Xing, W. J. Si, S. P. Zhuo, Xinxing Tan Cailiao/New Carbon Mater. 2010, 25, 370.

[151] Z. J. Zhang, D. H. Xie, P. Cui, X. Y. Chen, RSC Adv. 2014, 4, 6664.

[152] C. Bommier, R. Xu, W. Wang, X. Wang, D. Wen, J. Lu, X. Ji, Nano Energy 2015, 13, 709.

[153] C. Xia, S. Q. Shi, Green Chem. 2016, 18, 2063.

[154] W. Zhang, N. Lin, D. Liu, J. Xu, J. Sha, J. Yin, X. Tan, H. Yang, H. Lu, H. Lin, Energy 2017, 128, 618.

[155] B. Yang, D. Zhang, J. He, Y. Wang, K. Wang, H. Li, Y. Wang, L. Miao, R. Ren, M. Xie, Carbon Lett. 2020, 1, 11.

[156] L. M. Smith, S. Q. Shi, J. Shi, C. Wang, Y. Tan, H. Zhou, Wood Fiber Sci. 2020, 52, 191.

[157] Y. Zhang, S. Liu, X. Zheng, X. Wang, Y. Xu, H. Tang, F. Kang, Q. H. Yang, J. Luo, Adv. Funct. Mater. 2017, 27, 1604687.

[158] M. Inagaki, T. Nishikawa, K. Sakuratani, T. Katakura, H. Konno, E. Morozumi, Carbon 2004, 4, 890.

[159] E. Raymundo-Piñero, M. Cadek, F. Béguin, Adv. Funct. Mater. 2009, 19, 1032.

[160] P. Kleszyk, P. Ratajczak, P. Skowron, J. Jagiello, Q. Abbas, E. Frąckowiak, F. Béguin, Carbon 2015, 81, 148.

[161] S. Gao, K. Geng, H. Liu, X. Wei, M. Zhang, P. Wang, J. Wang, Energy Environ. Sci. 2015, 8, 221.

[162] J. Liu, S. Min, F. Wang, Z. Zhang, J. Power Sources 2020, 466, 228347.

[163] H. Liu, M. Jia, S. Yue, B. Cao, Q. Zhu, N. Sun, B. Xu, J. Mater. Chem. A 2017, 5, 9572.

[164] Y. Wang, X. Jiang, ACS Appl. Mater. Interfaces 2013, 5, 11597.

[165] C. Wang, D. Wu, H. Wang, Z. Gao, F. Xu, K. Jiang, J. Mater. Chem. A 2018, 6, 1244.

[166] C. Wang, D. Wu, H. Wang, Z. Gao, F. Xu, K. Jiang, J. Power Sources 2017, 363, 375.

[167] M. P. Bichat, E. Raymundo-Piñero, F. Béguin, Carbon 2010, 48, 4351.

[168] Y. D. Chen, M. J. Huang, B. Huang, X. R. Chen, J. Anal. Appl. Pyrolysis 2012, 98, 159.

[169] M. Biswal, A. Banerjee, M. Deo, S. Ogale, Energy Environ. Sci. 2013, 6, 1249.

[170] Z. Li, W. Lv, C. Zhang, B. Li, F. Kang, Q. H. Yang, Carbon 2015, 92, 11.

[171] J. He, D. Zhang, M. Han, X. Liu, Y. Wang, Y. Li, X. Zhang, K. Wang, H. Feng, Y. Wang, J. Energy Storage 2019, 21, 94.

[172] C. Leng, K. Sun, J. Li, J. Jiang, ACS Sustain. Chem. Eng. 2017, 5, 10474.

[173] J. Niu, R. Shao, J. Liang, M. Dou, Z. Li, Y. Huang, F. Wang, Nano Energy 2017, 36, 322. 